Supporting Information

\title{
Amphiphilic Diazapyrenes with Multiple Stimuli-Responsive Properties
}

\author{
Chunchun Liang, ${ }^{\text {Mengwei Li, }}$, Yulan Chen
}

Department of Chemistry, Institute of Molecular Plus, Tianjin University, Tianjin 300354, P. R. China.

\# These authors contributed equally to this work.

*E-mail: yulan.chen@tju.edu.cn 


\section{Materials and Method}

General: Unless otherwise noted, all chemicals were purchased from Aldrich, Acros or Adamas and used without further purification. Dichloromethane $\left(\mathrm{CH}_{2} \mathrm{Cl}_{2}\right)$ was distilled over $\mathrm{CaH}_{2}$. Tetrahydrofuran (THF) was distilled over sodium and benzophenone. All reactions were performed under an atmosphere of nitrogen and monitored by TLC with silica gel. Column chromatography was carried out on silica gel (200-300 mesh). The catalyst precursor $\mathrm{Pd}\left(\mathrm{PPh}_{3}\right)_{4}$ and was prepared according to the literature ${ }^{1}$ and stored in a Schlenk tube under nitrogen atmosphere. The 2,7-Bis(4,4,5,5-tetramethyl-1,3,2-dioxaborolan-2-yl)pyrene $\left(\mathrm{D}_{1}\right)$ was prepared according to the literature. ${ }^{2}$

Measurements: ${ }^{1} \mathrm{H}$ NMR $(400 \mathrm{MHz})$ and ${ }^{13} \mathrm{C}$ NMR $(101 \mathrm{MHz})$ spectra were recorded on a $400 \mathrm{MHz}$ Bruker AV400 spectrometer in $\mathrm{CDCl}_{3}$. The UV-Vis absorption spectra were obtained on a PerkinElmer Lambda 750 spectrophotometer. Fluorescence spectra were recorded on a Hitachi F-7000 fluorescence spectrophotometer. XRD patterns were collected by using a Rigaku D/Max-2500 diffractometer. Field emission scanning electron microscopies (FE-SEM) were performed on a Hitachi Limited model SU800 microscope operating at an accelerating voltage of $10 \mathrm{kV}$. Samples for SEM measurements were prepared by transferring the stock aqueous solution to silicon wafers by drop-casting method followed by water evaporation. Polarizing optical microscopy (POM) images were obtained on an Olympus BH-2 optical microscope with a Mettler hot stage (FP-52) and an automatic Nikon DS-Ri2 camera. Fourier transform infrared (FT-IR) spectra were collected in reflection mode on a Bruker Alpha spectrometer with a scan range of $400-4000 \mathrm{~cm}^{-1}$. Melting points were measured on a SGW X-4A. The transient fluorescence decay curves of DPy-3-C1 and DPy-3-C5 were measured on an Edinburgh FLS 1000 fluorescence spectrometer. 

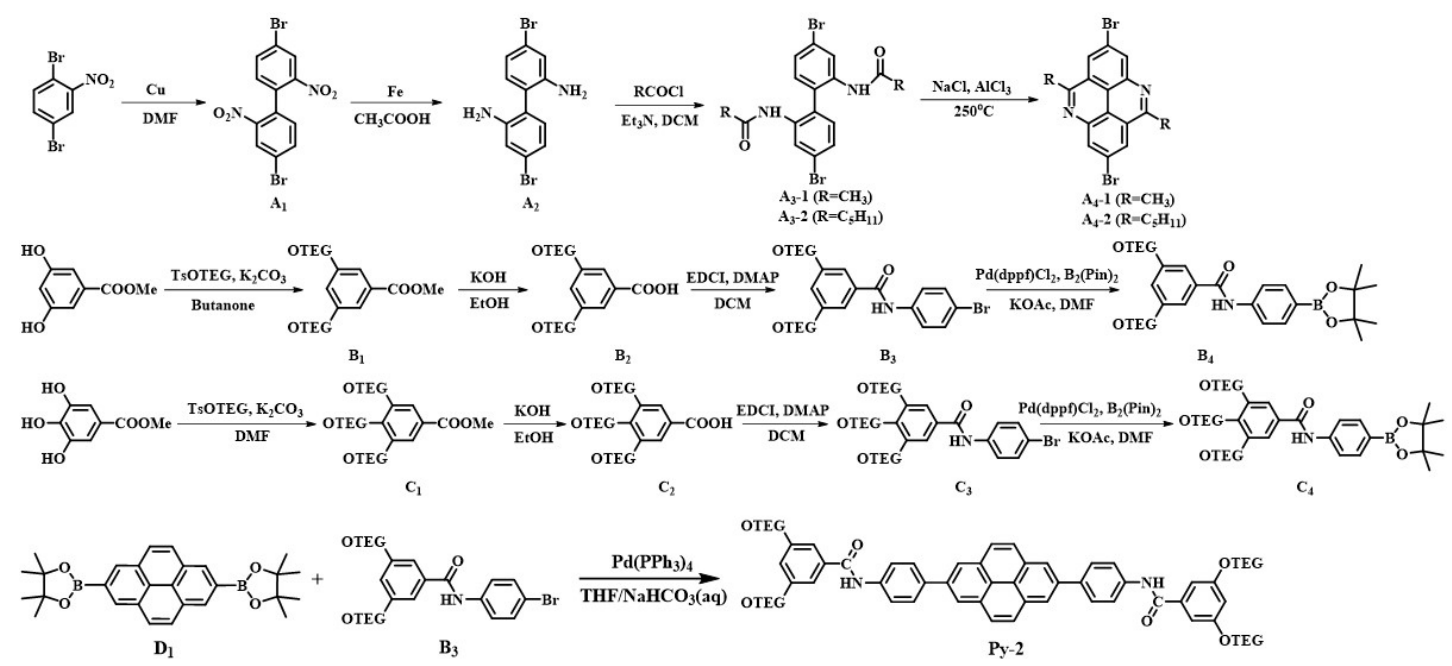

Scheme S1. Synthetic routes of $\mathrm{A}_{4}-1, \mathrm{~A}_{4}-2, \mathrm{~B}_{4}, \mathrm{C}_{4}$ and Py-2. 


\section{Supporting Figures}
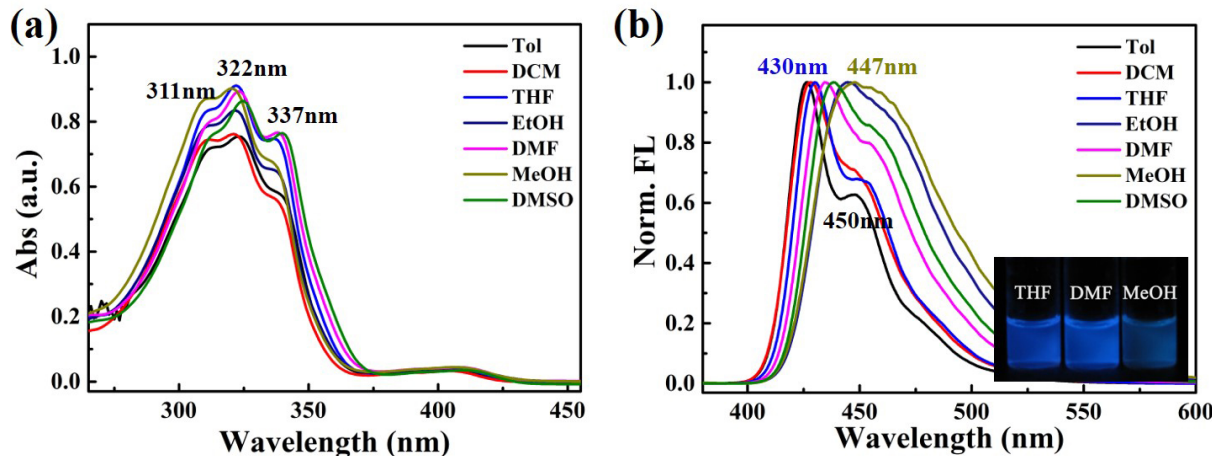

Figure S1. (a) UV-Vis absorption and (b) fluorescence spectra of DPy-2-C1 in different solvents (concentration: $8.0 \times 10^{-6} \mathrm{M}, \lambda_{\mathrm{ex}}=322 \mathrm{~nm}$ ).
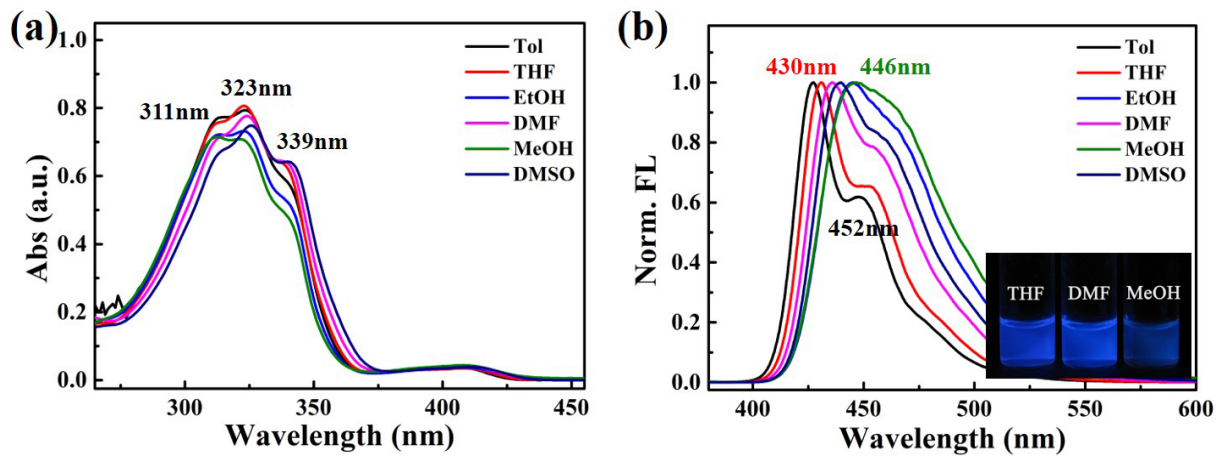

Figure S2. (a) UV-Vis absorption and (b) fluorescence spectra of DPy-2-C5 in different solvents (concentration: $7.0 \times 10^{-6} \mathrm{M}, \lambda_{\mathrm{ex}}=322 \mathrm{~nm}$ ).
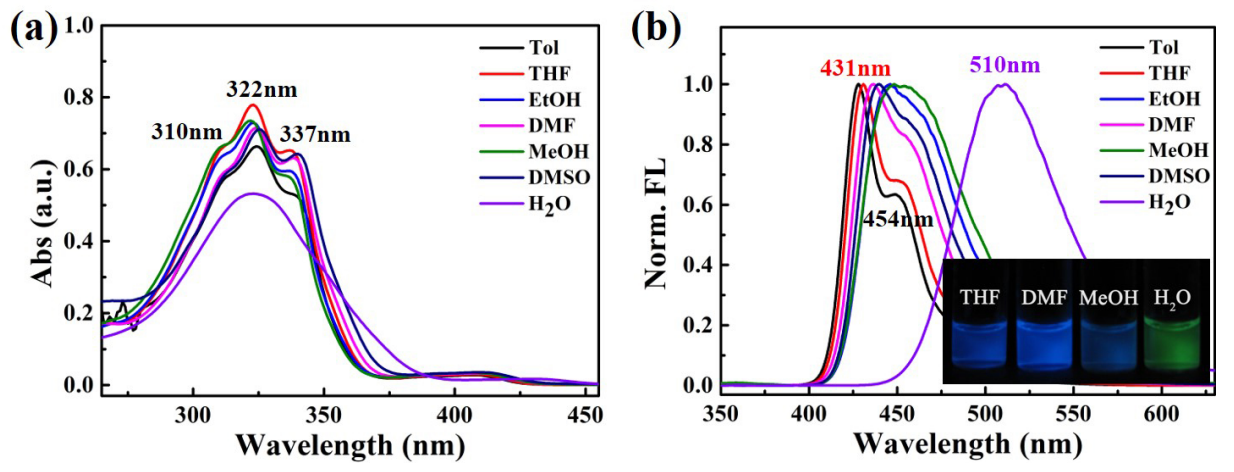

Figure S3. (a) UV-Vis absorption and (b) fluorescence spectra of DPy-3-C1 in different solvents (concentration: $6.0 \times 10^{-6} \mathrm{M}, \lambda_{\mathrm{ex}}=322 \mathrm{~nm}$ ). 

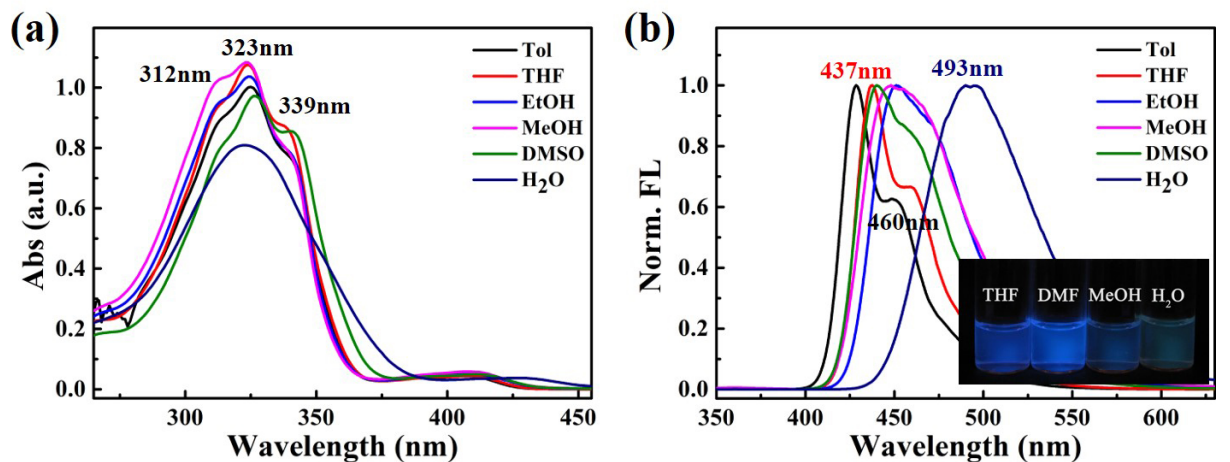

Figure S4. (a) UV-Vis absorption and (b) fluorescence spectra of DPy-3-C5 in different solvents (concentration: $6.0 \times 10^{-6} \mathrm{M}, \lambda_{\mathrm{ex}}=322 \mathrm{~nm}$ ).
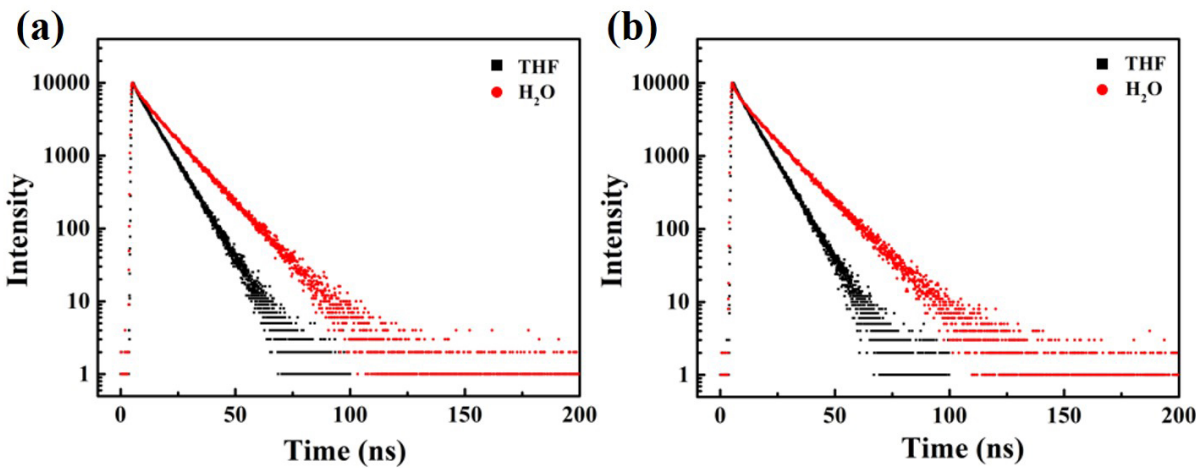

\begin{tabular}{|c|c|c|c|c|c|}
\hline solvent & $\begin{array}{c}\tau_{1} \\
(\mathrm{~ns})\end{array}$ & $\begin{array}{c}\tau_{2} \\
(\mathrm{~ns})\end{array}$ & $\mathrm{A}_{1} / \mathrm{A}_{2}$ & $\chi^{2}$ & $\begin{array}{c}<\tau> \\
(\mathrm{ns})\end{array}$ \\
\hline THF & 1.58 & 8.19 & $2 / 98$ & 1.03 & 7.47 \\
\hline $\mathrm{H}_{2} \mathrm{O}$ & 3.69 & 12.76 & $8 / 92$ & 0.89 & 10.75 \\
\hline
\end{tabular}

\begin{tabular}{|c|c|c|c|c|c|}
\hline solvent & $\begin{array}{c}\tau_{1} \\
(\mathrm{~ns})\end{array}$ & $\begin{array}{c}\tau_{2} \\
(\mathrm{~ns})\end{array}$ & $\mathrm{A}_{1} / \mathrm{A}_{2}$ & $\chi^{2}$ & $\begin{array}{c}<\tau> \\
(\mathrm{ns})\end{array}$ \\
\hline THF & 1.12 & 8.03 & $1 / 99$ & 1.03 & 7.37 \\
\hline $\mathrm{H}_{2} \mathrm{O}$ & 3.21 & 13.37 & $9 / 91$ & 0.92 & 10.37 \\
\hline
\end{tabular}

Figure S5. Fluorescence decay curves (top) and the corresponding data (bottom) of (a) DPy-3-C1 and (b) DPy-3-C5 in THF and water $\left(\lambda_{\mathrm{ex}}=365 \mathrm{~nm}\right)$. 

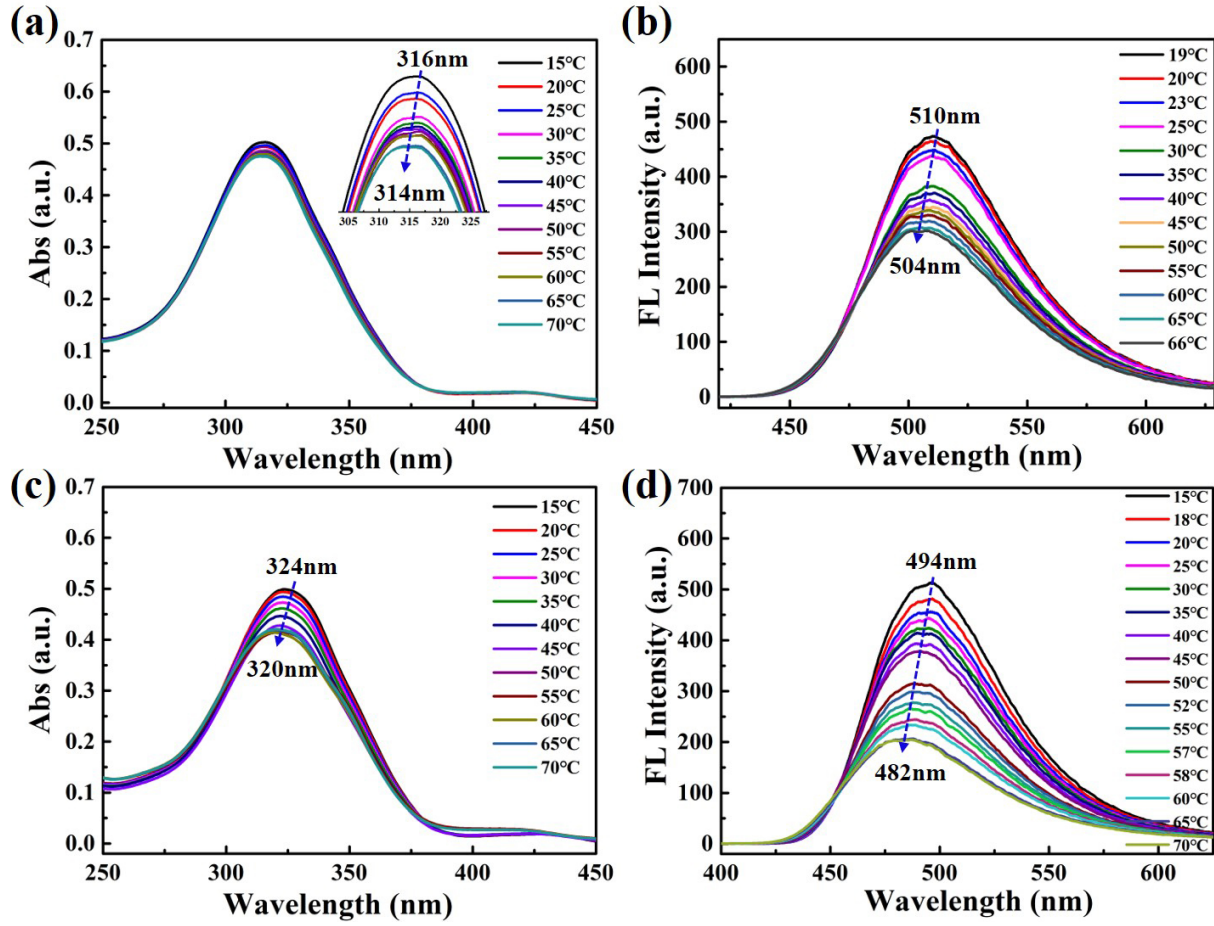

Figure S6. Temperature-dependent (a, c) UV-Vis absorption and (b, d) fluorescence spectra of (a, b) DPy-3-C1 and (c, d) DPy-3-C5 in water (concentration: $6.0 \times 10^{-6} \mathrm{M}, \lambda_{\mathrm{ex}}=322 \mathrm{~nm}$ ).
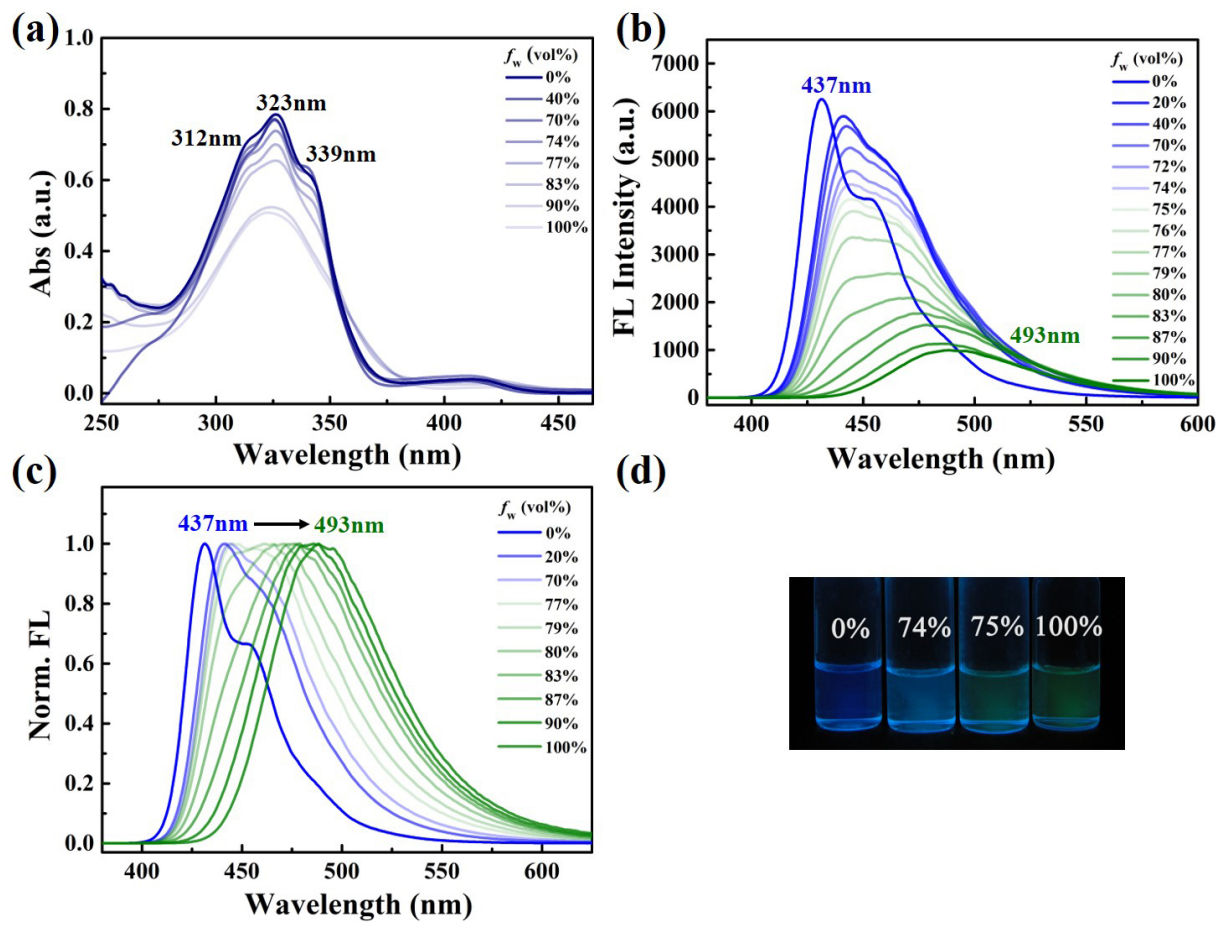

(d)

Wavelength $(\mathrm{nm})$

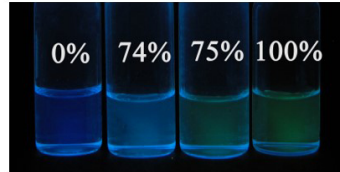

Figure S7. (a) UV-Vis absorption and (b, c) fluorescence spectra of DPy-3-C5 in THF/water mixtures with different water fractions, and (d) the corresponding photographic images taken under $365 \mathrm{~nm}$ UV light irradiation (concentration: $6.0 \times 10^{-6} \mathrm{M}, \lambda_{\mathrm{ex}}=322 \mathrm{~nm}$ ). 

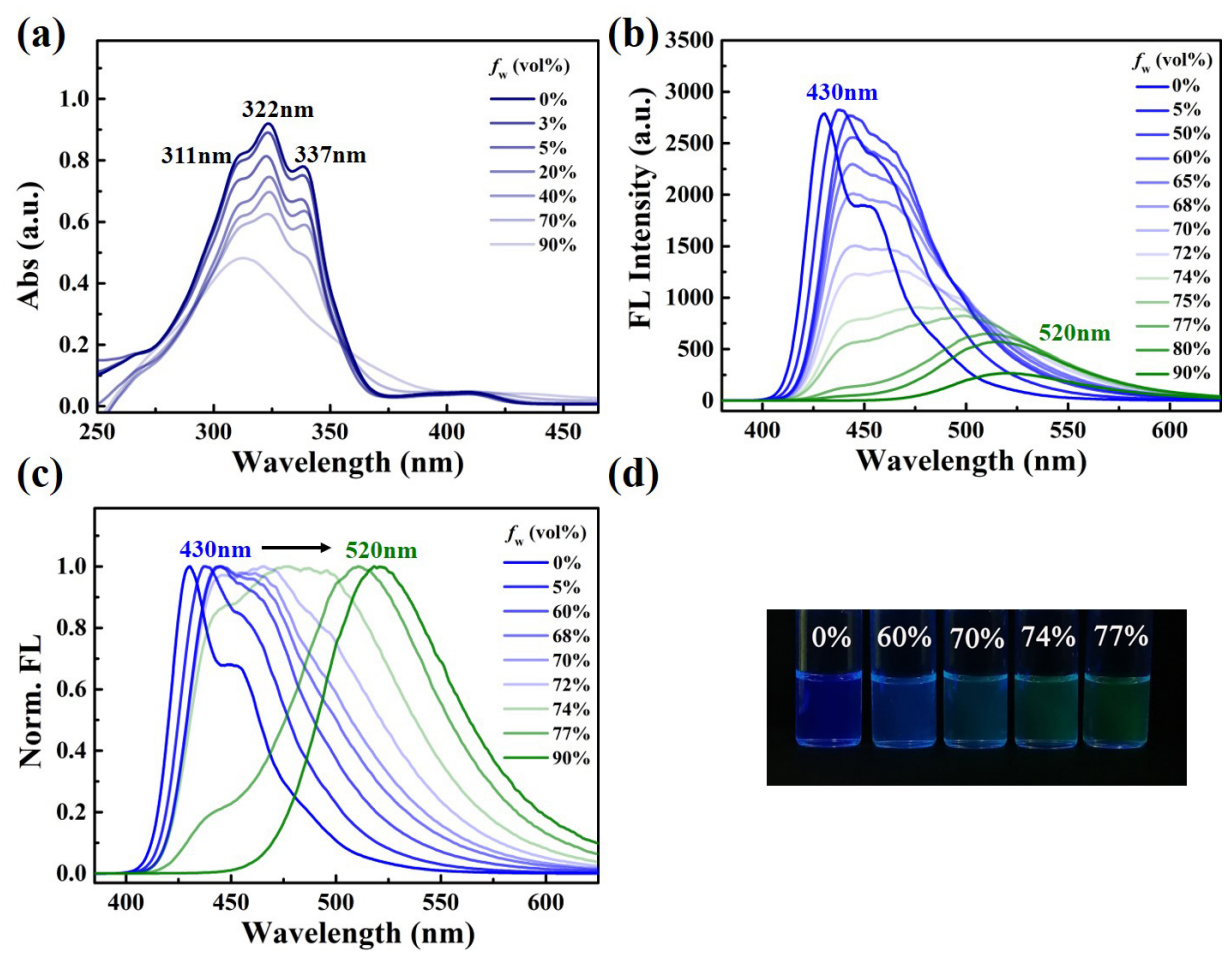

Figure S8. (a) UV-Vis absorption and (b, c) fluorescence spectra of DPy-2-C1 in THF/water mixtures with different water fractions, and (d) the corresponding photographic images taken under $365 \mathrm{~nm}$ UV light irradiation (concentration: $8.0 \times 10^{-6} \mathrm{M}, \lambda_{\mathrm{ex}}=322 \mathrm{~nm}$ ).
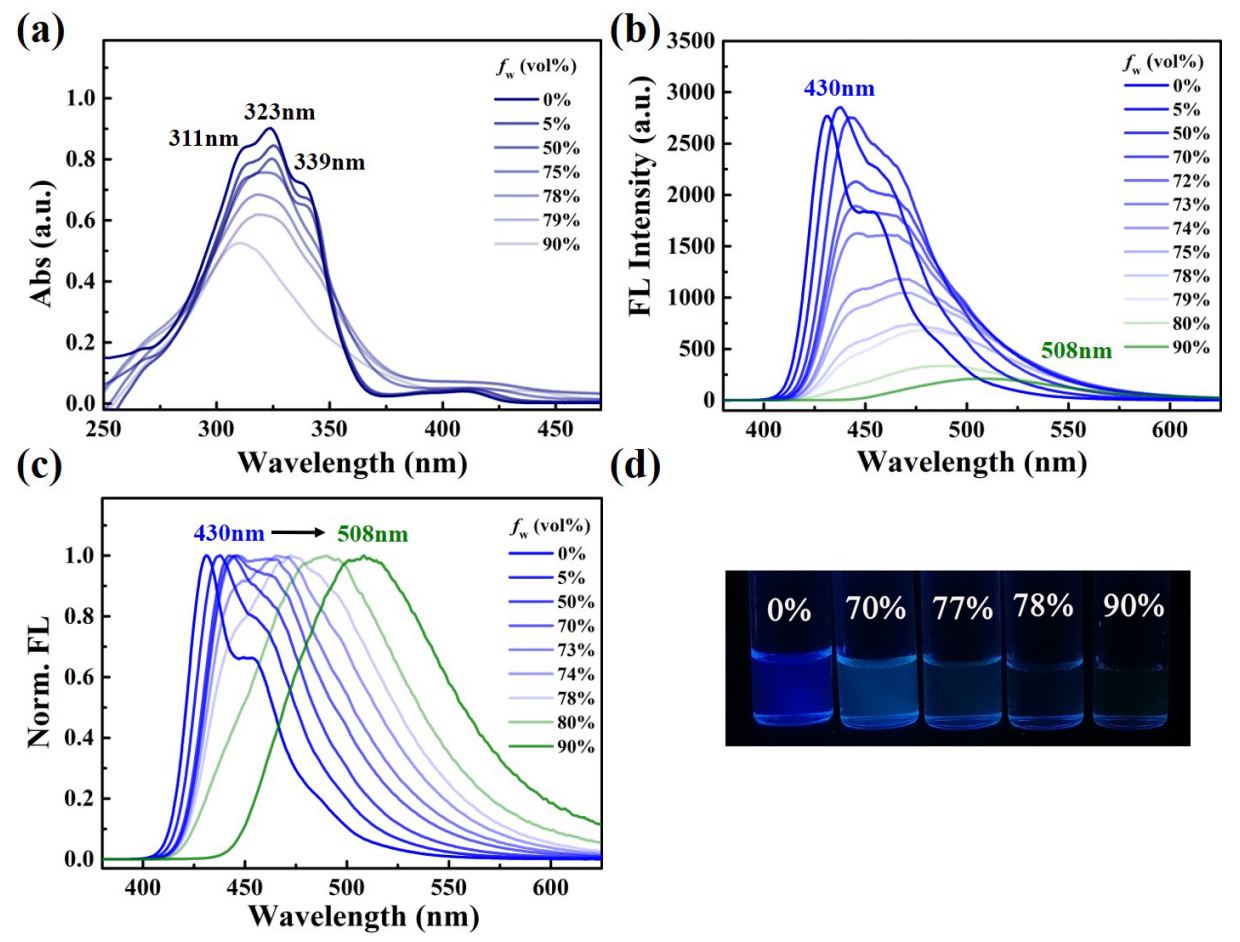

Figure S9. (a) UV-Vis absorption and (b, c) fluorescence spectra of DPy-2-C5 in THF/water mixtures with different water fractions, and (d) the corresponding photographic images taken under $365 \mathrm{~nm}$ UV light irradiation (concentration: $7.0 \times 10^{-6} \mathrm{M}, \lambda_{\mathrm{ex}}=322 \mathrm{~nm}$ ). 
(a)

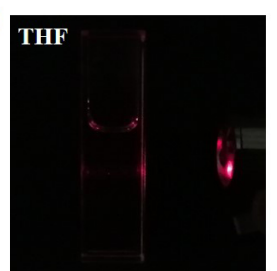

(c)

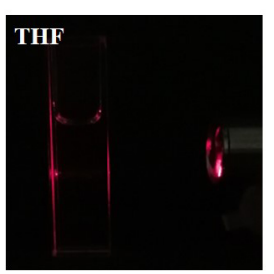

(d)

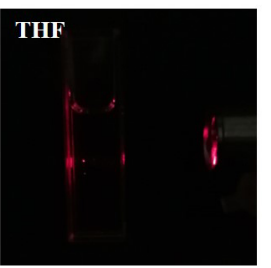

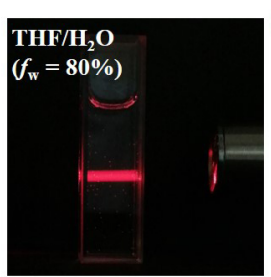
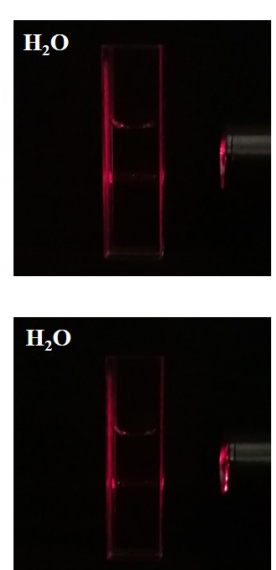
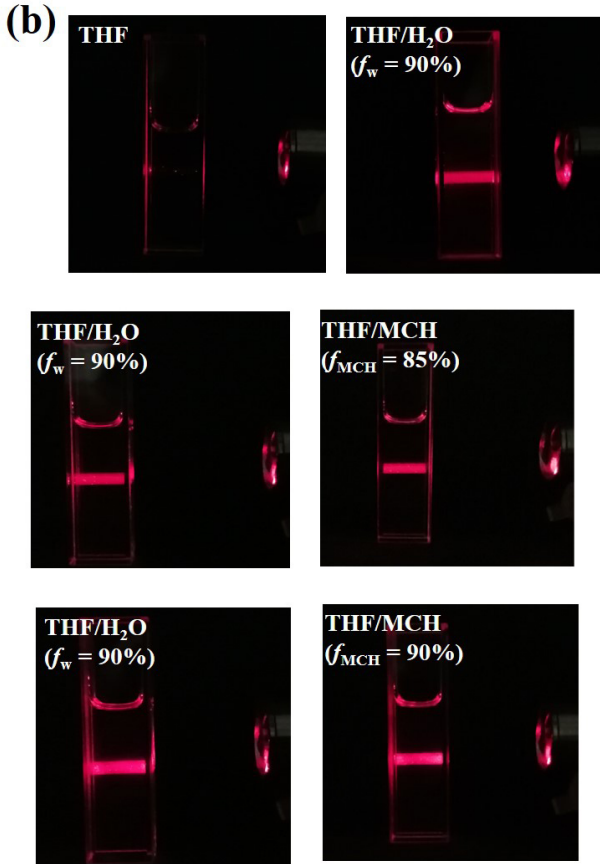

Figure S10. The Tyndall effect of (a) DPy-2-C1, (b) DPy-2-C5, (c) DPy-3-C1, (d) DPy-3-C5 in different solutions.

(a)

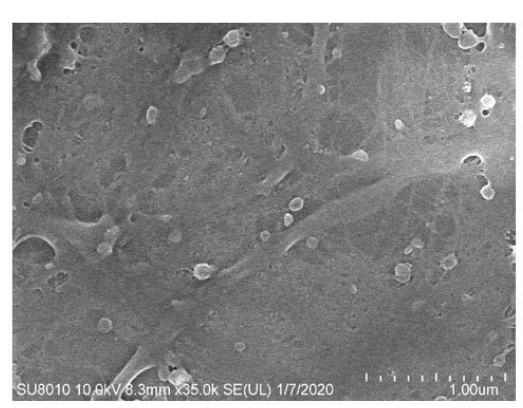

(b)

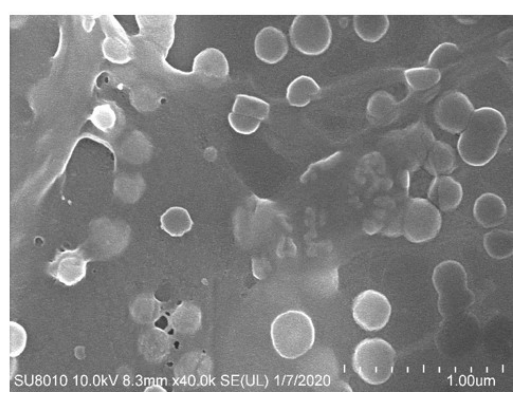

Figure S11. SEM images of (a) DPy-3-C1 and (b) DPy-3-C5 preapared in water.

(a)

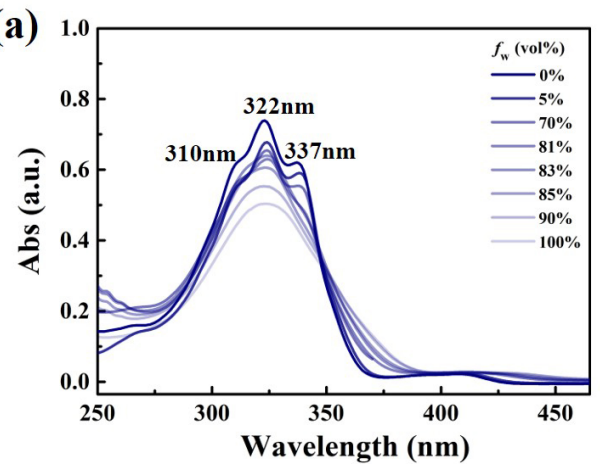

(b)

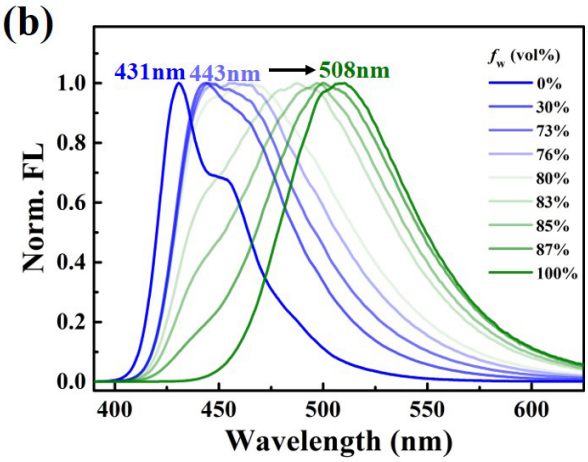

Figure S12. (a) UV-Vis absorption and (b) fluorescence spectra of DPy-3-C1 in THF/water mixtures with different water fractions (concentration: $6.0 \times 10^{-6} \mathrm{M}, \lambda_{\mathrm{ex}}=322 \mathrm{~nm}$ ). 

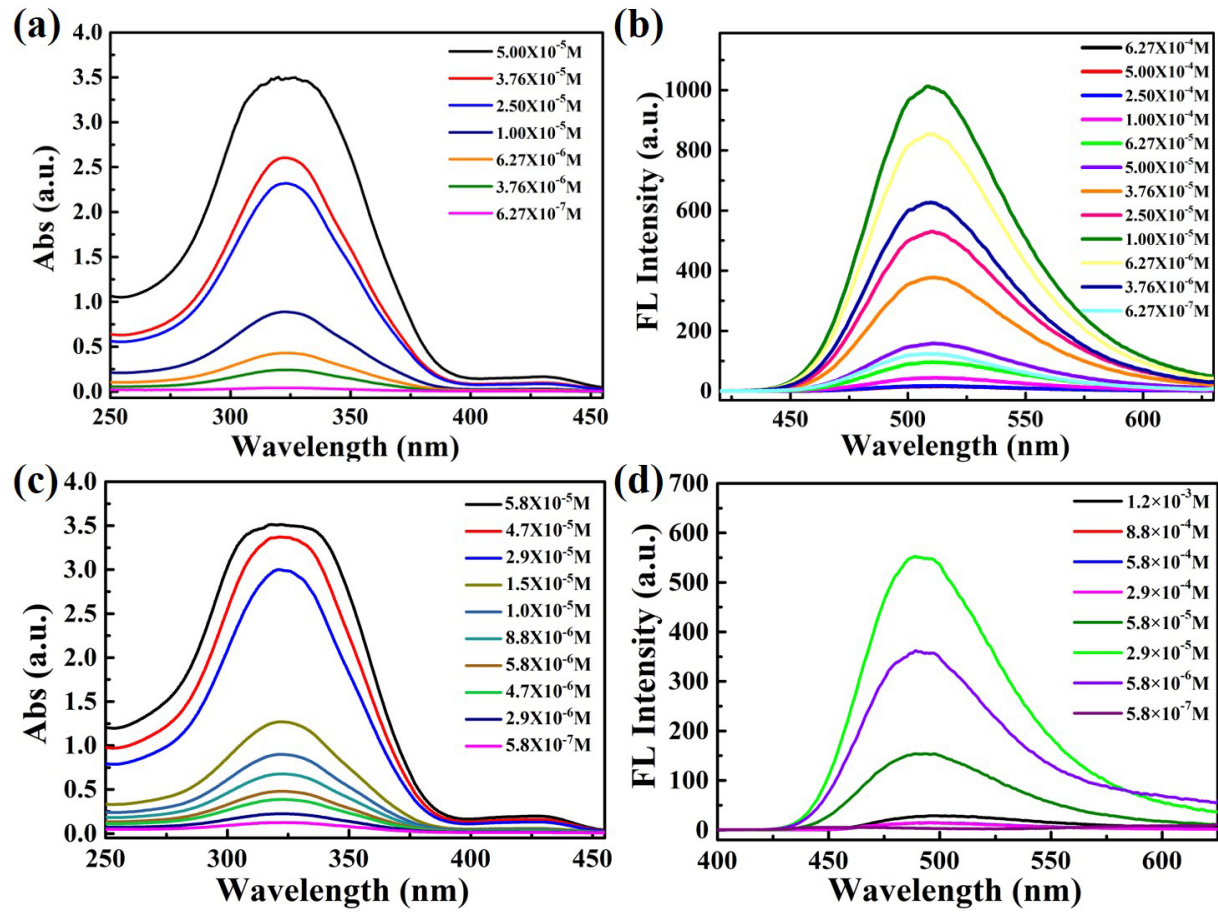

Figure S13. Concentration-dependent (a, c) UV-Vis spectra and (b, d) fluorescence spectra of (a, b) DPy-3-C1 and (c, d) DPy-3-C5 in water $\left(\lambda_{\text {ex }}=322 \mathrm{~nm}\right)$.

(a)
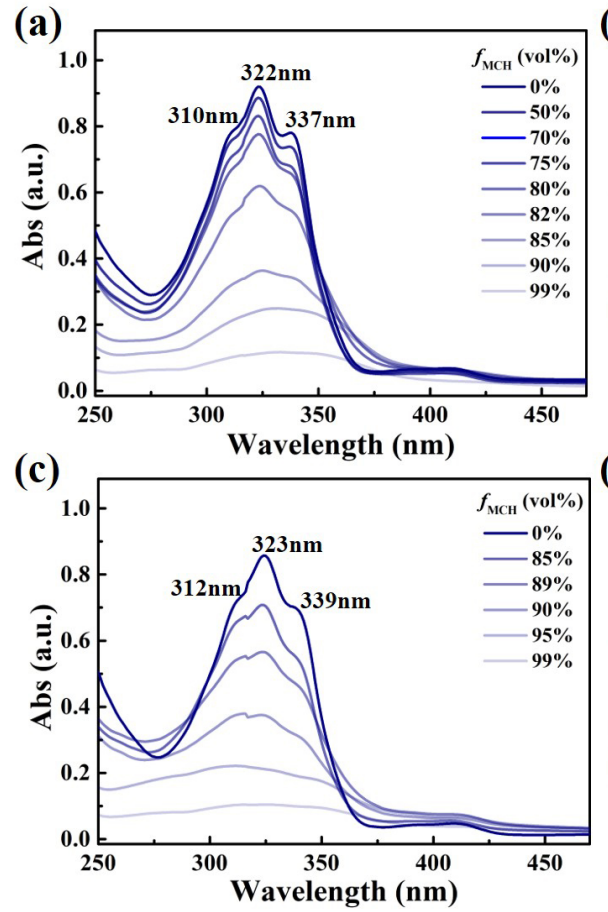

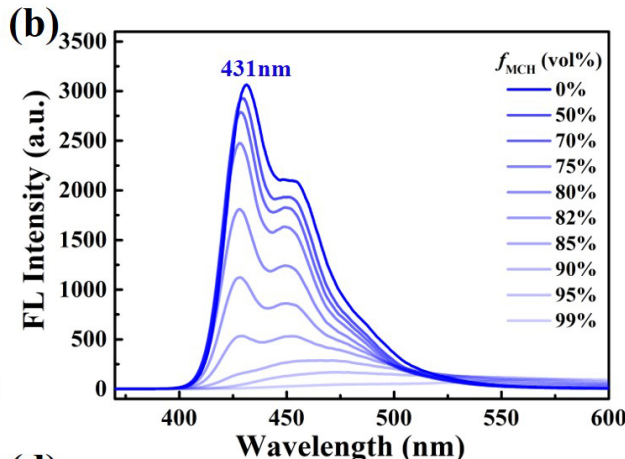

(d)

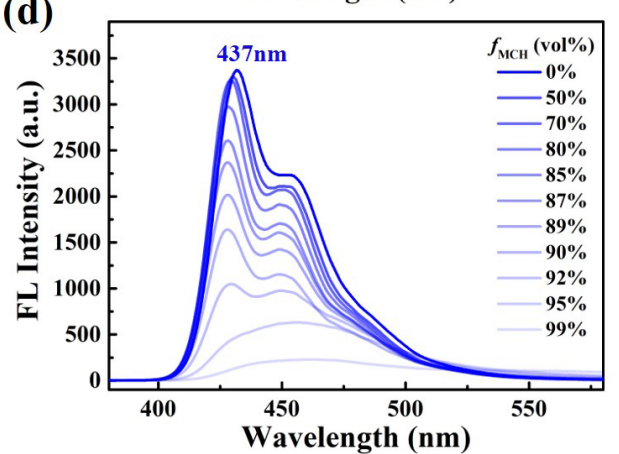

Figure S14. (a, c) UV-Vis absorption and (b, d) fluorescence spectra of (a, b) DPy-3-C1 and (c, d) DPy-3-C5 in THF/MCH mixtures with different methylcyclohexane fractions $\left(f_{\mathrm{MCH}}\right)$ (concentration: $6.0 \times 10^{-6} \mathrm{M}, \lambda_{\mathrm{ex}}=322 \mathrm{~nm}$ ). 

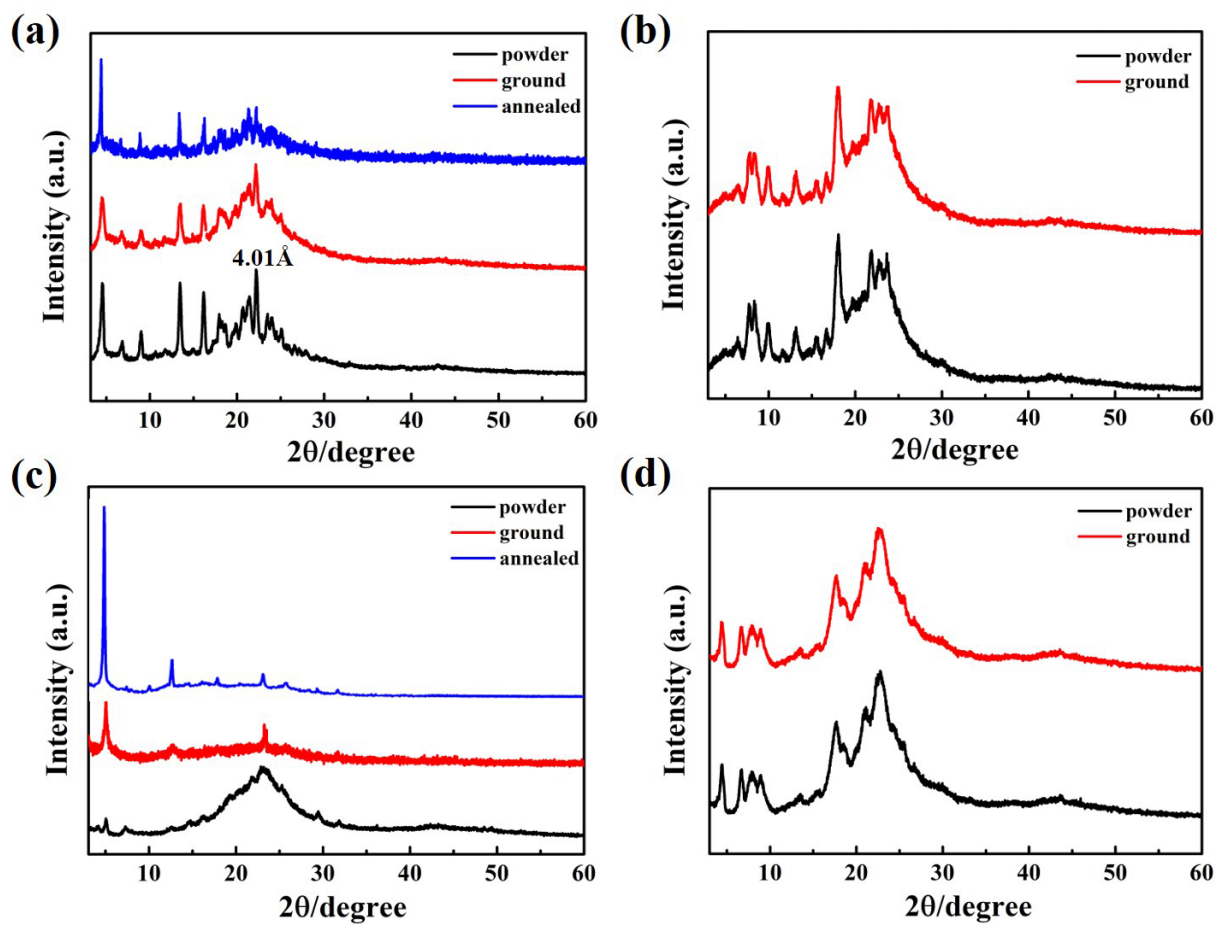

(d)

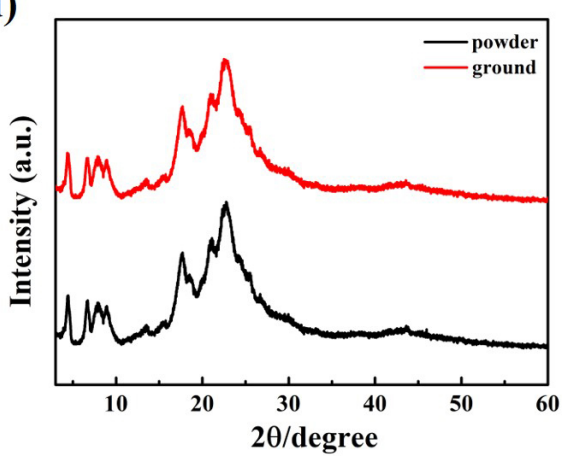

Figure S15. XRD profiles of (a) DPy-2-C1, (b) DPy-2-C5, (c) DPy-3-C1 and (d) DPy-3-C5 in different states.
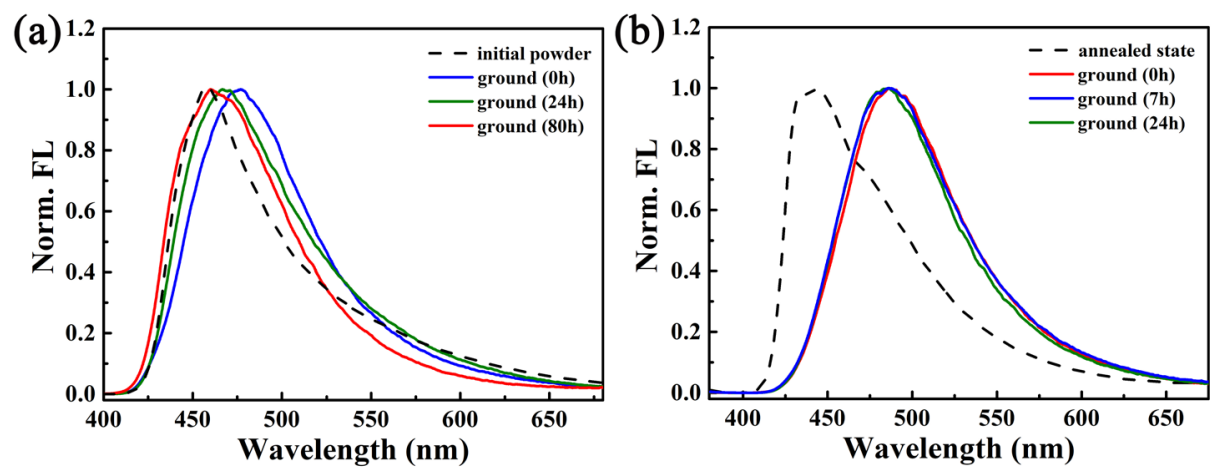

Figure S16. Time-dependent fluorescence spectra of (a) DPy-2-C1 and (b) DPy-3-C1 after triggered by grinding (temperature: $22-23^{\circ} \mathrm{C}$ ). 

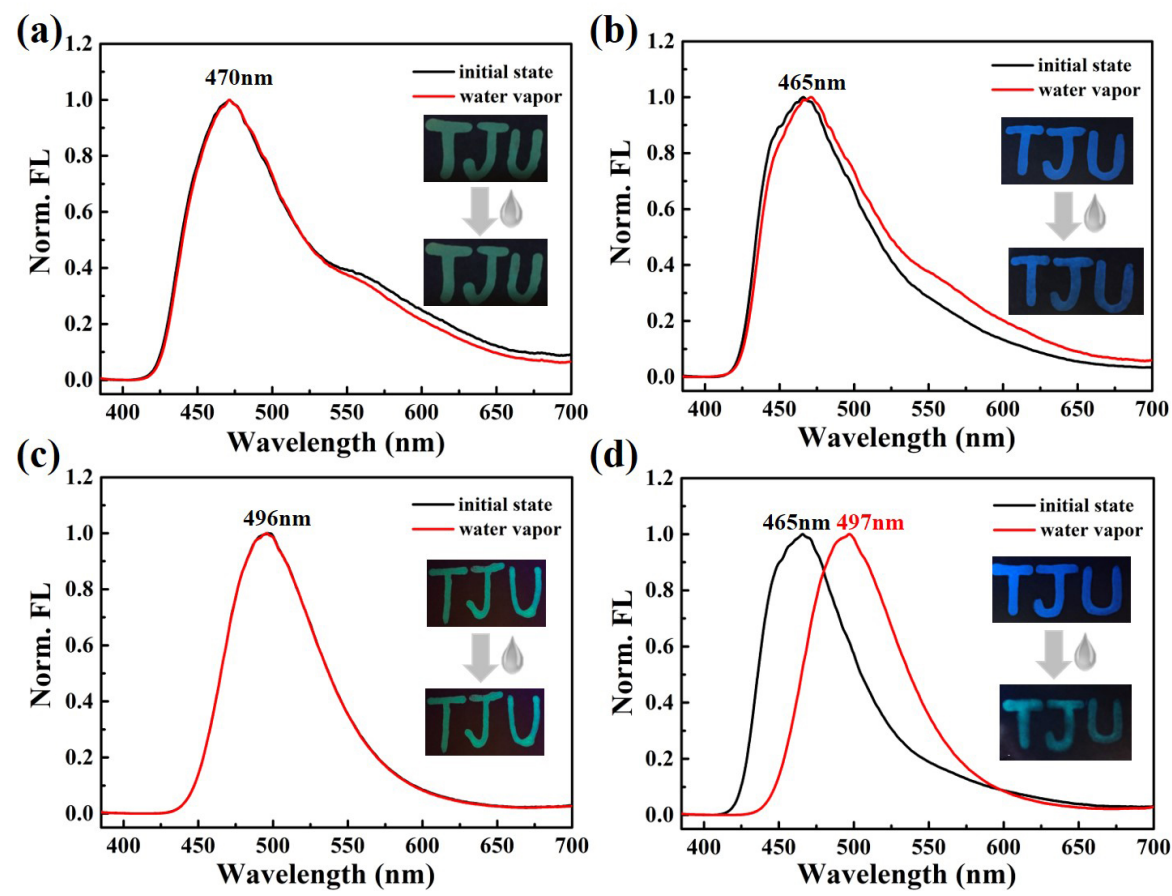

Figure S17. Fluorescence spectra and the corresponding photographs of the filter papers deposited with (a) DPy-2-C1, (b) DPy-2-C5, (c) DPy-3-C1 and (d) DPy-3-C5 before and after treatment with water vapor $\left(\lambda_{\mathrm{ex}}=365 \mathrm{~nm}\right)$.

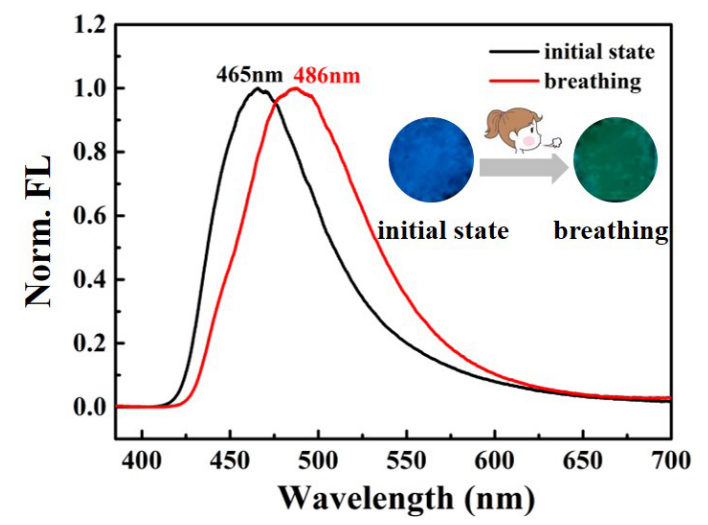

Figure S18. Fluorescence spectra of the DPy-3-C5 film deposited on a glass-plate before and after treatment with the exhaled gas from the mouth $\left(\lambda_{\mathrm{ex}}=365 \mathrm{~nm}\right)$.
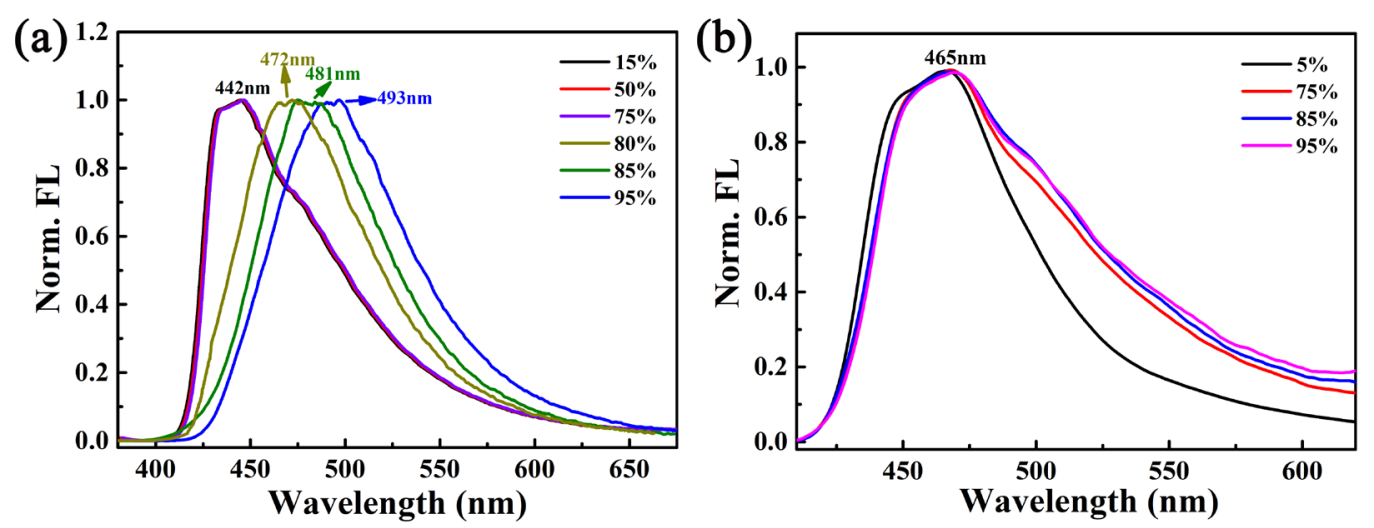

Figure S19. Fluorescence spectra of (a) annealed DPy-3-C1 and (b) DPy-3-C5 at different humidities. 


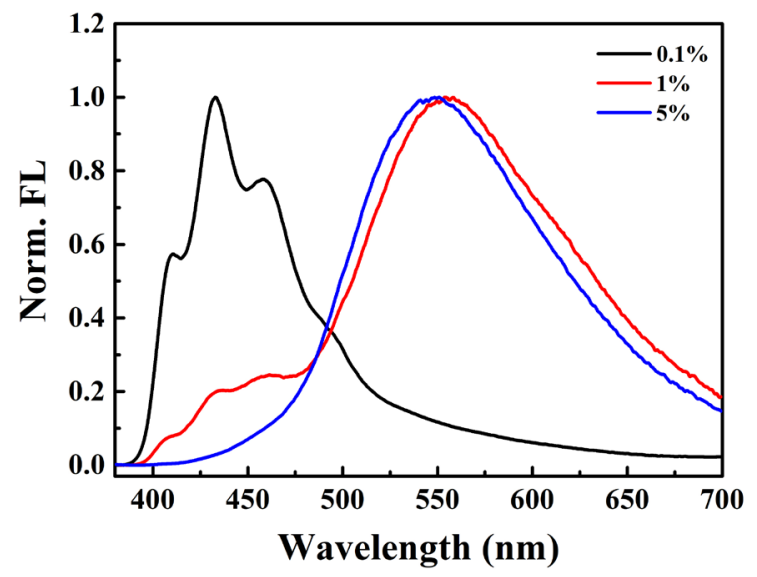

Figure S20. Fluorescence spectra of DPy-2-C1/poly(lactic acid) blends at $0.1 \mathrm{wt} \%, 1 \%$ and $5 \mathrm{wt} \%$ dye loadings $\left(\lambda_{\mathrm{ex}}=365 \mathrm{~nm}\right)$.
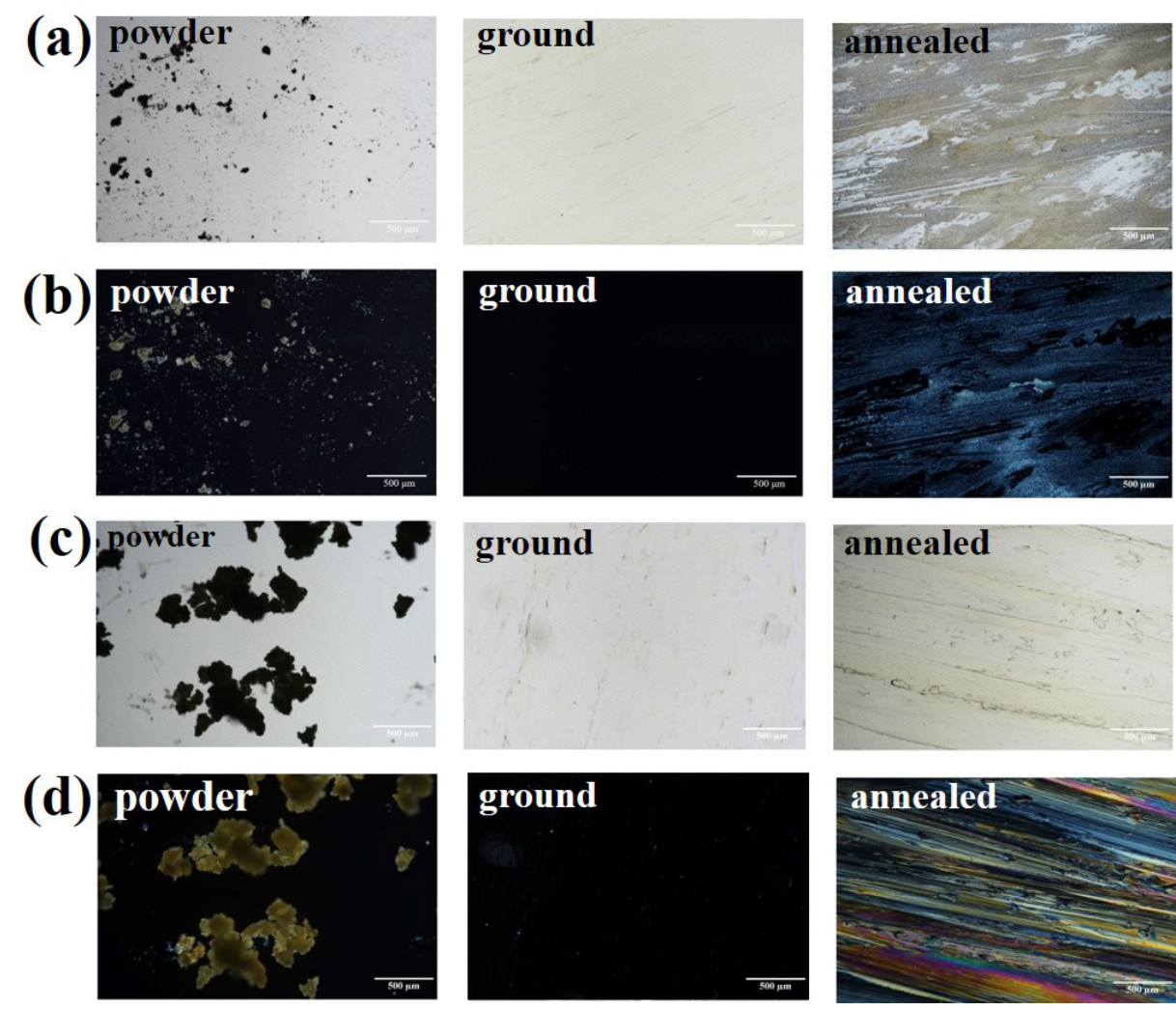

Figure S21. (a, c) Optical microscope and (b, d) polarizing optical microscope (POM) images of (a, b) DPy-2-C1 and (c, d) DPy-3-C1 in powder, ground and annealed states. 
(a)
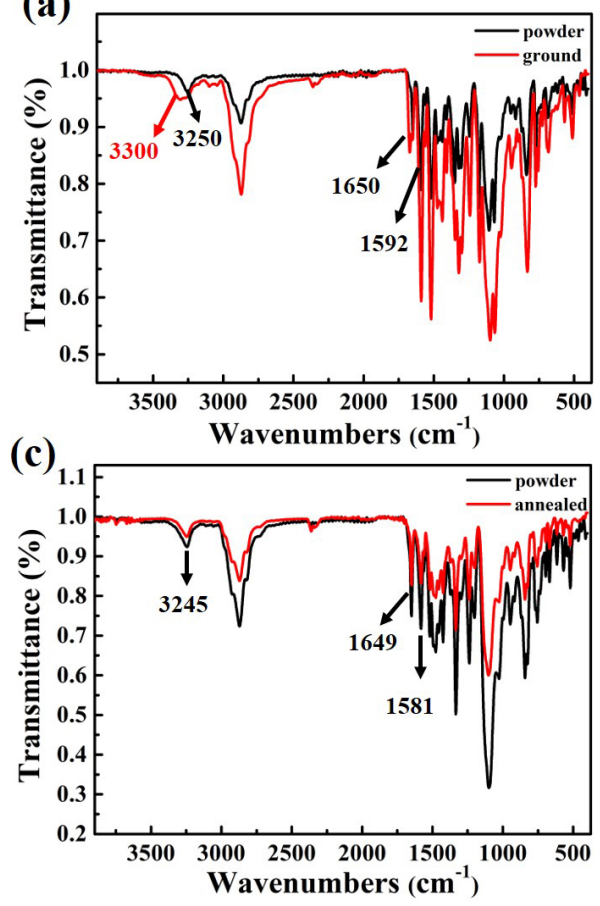

(b)

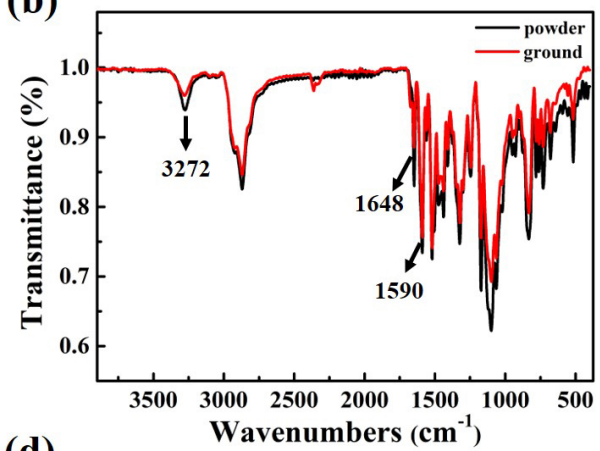

(d)

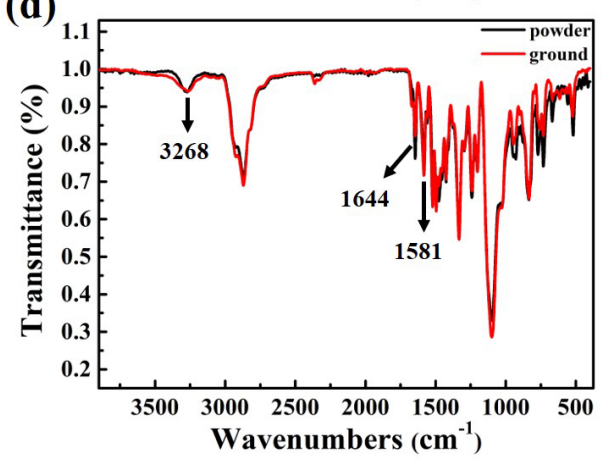

Figure S22. FT-IR spectra of (a) DPy-2-C1, (b) DPy-2-C5, (c) DPy-3-C1 and (d) DPy-3-C5 in different states.

(a)

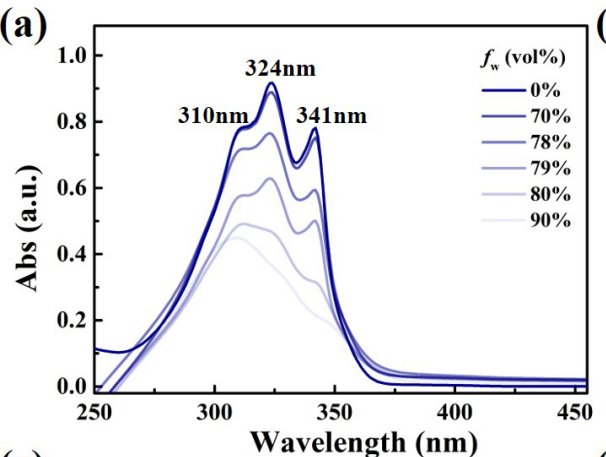

(c)

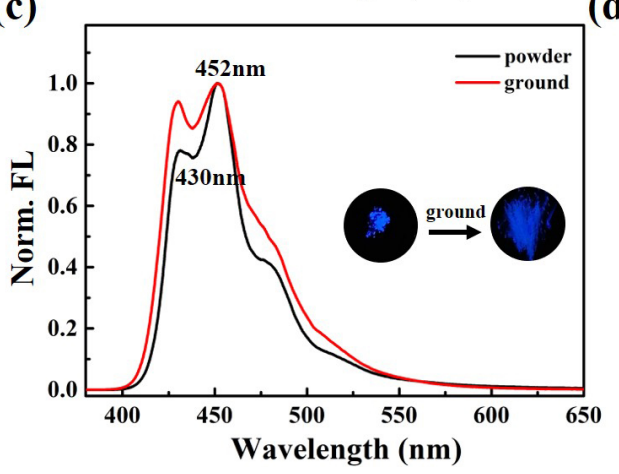

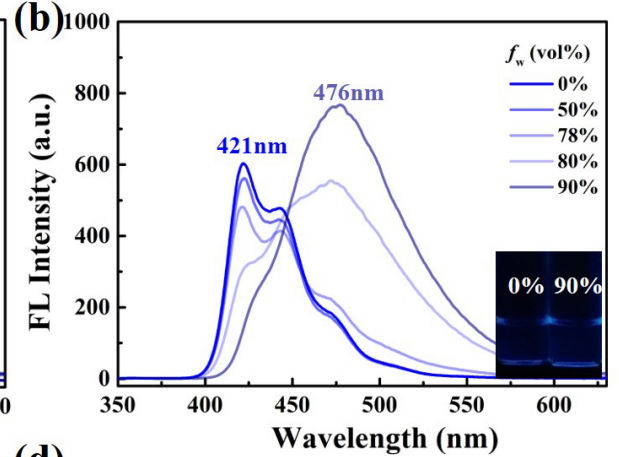

(d)

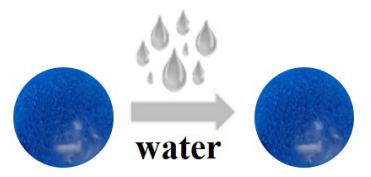

Figure S23. (a) UV-Vis absorption and (b) fluorescence spectra of $\mathbf{P y - 2}$ in THF/water mixtures with different water fractions (concentration: $6.0 \times 10^{-6} \mathrm{M}, \lambda_{\mathrm{ex}}=323 \mathrm{~nm}$ ). (c) Fluorescence spectra of Py-2 in different states $\left(\lambda_{\mathrm{ex}}=365 \mathrm{~nm}\right.$, inset: the corresponding photographic images taken under the irradiation of $365 \mathrm{~nm}$ UV light) and (d) photographic images of physical mixture of diazapyrene core with TEG before and after the stimulus of water vapor under $365 \mathrm{~nm}$ UV light irradiation. 


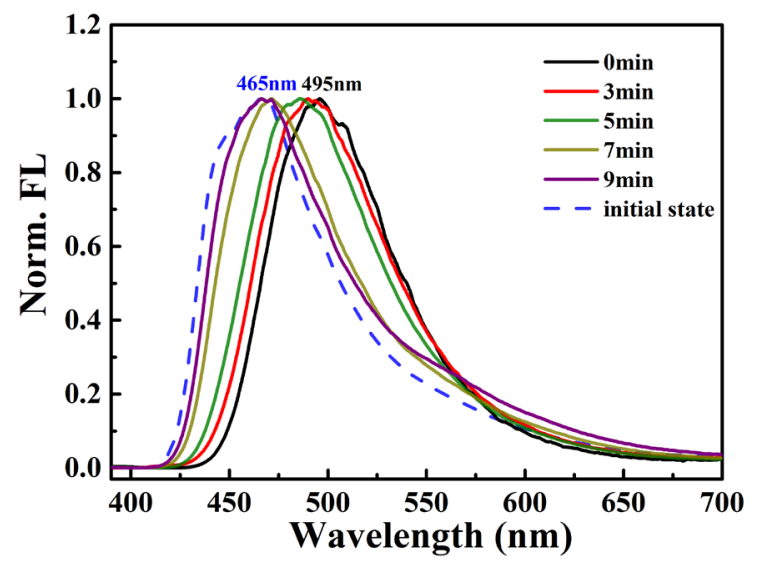

Figure S24. Time-dependent fluorescence spectra of DPy-3-C5 after fumed with water vapor (temperature: $22{ }^{\circ} \mathrm{C}$, relative humidity: $29 \%$ ).

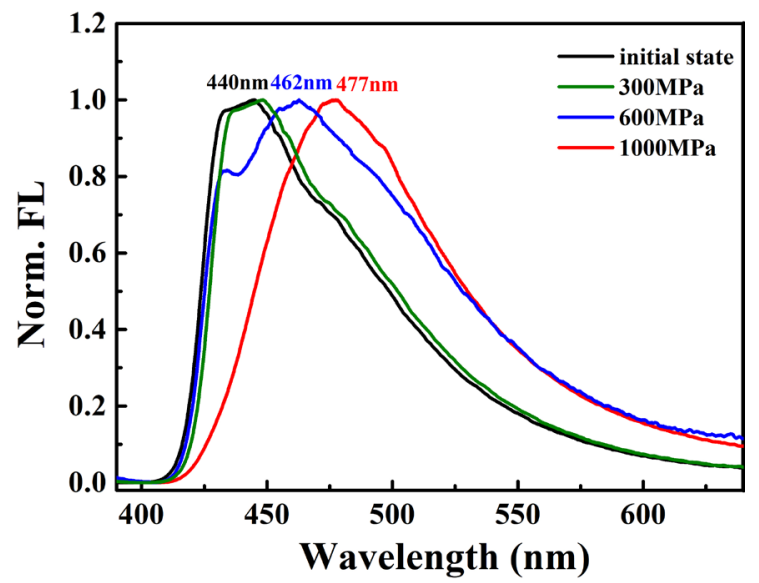

Figure S25. Pressure-dependent fluorescence spectra of annealed DPy-3-C1 powder. 
NMR Spectra

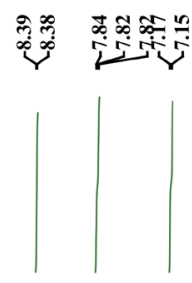

(Br

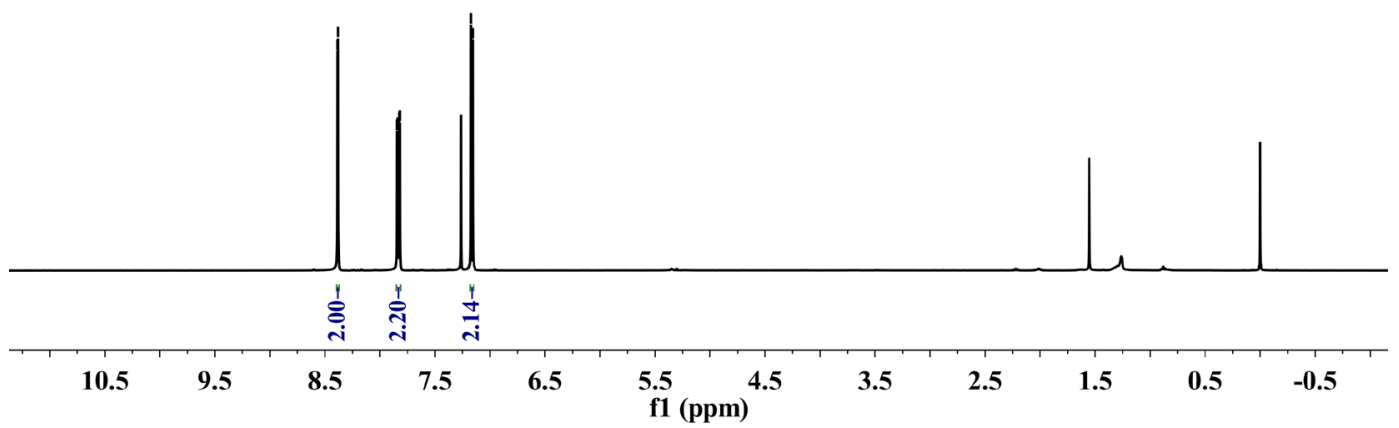

Figure S26. ${ }^{1} \mathrm{H}$ NMR spectrum of $\mathbf{A}_{\mathbf{1}}$ in $\mathrm{CDCl}_{3}$.

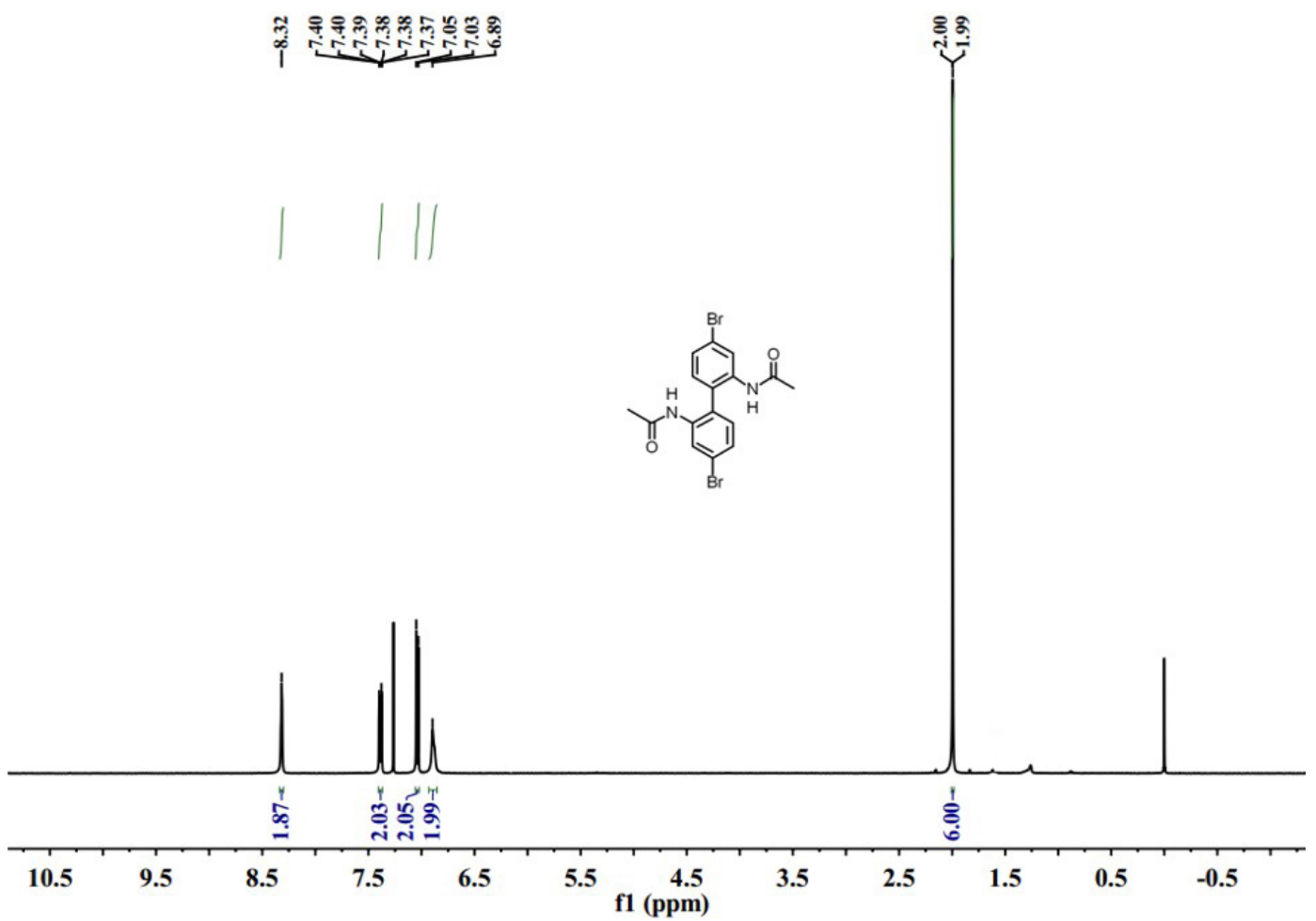

Figure S27. ${ }^{1} \mathrm{H}$ NMR spectrum of $\mathbf{A}_{\mathbf{3}} \mathbf{- 1}$ in $\mathrm{CDCl}_{3}$. 

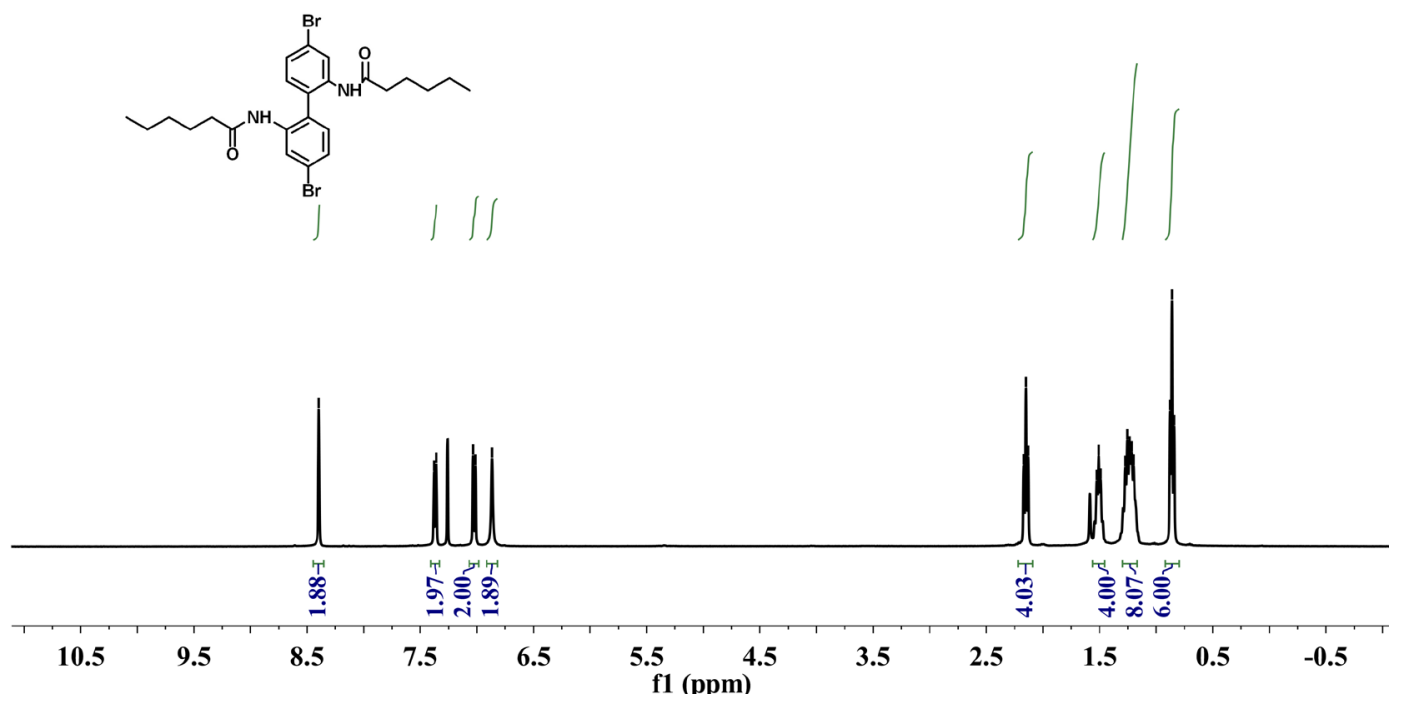

Figure S28. ${ }^{1} \mathrm{H}$ NMR spectrum of $\mathbf{A}_{\mathbf{3}} \mathbf{- 2}$ in $\mathrm{CDCl}_{3}$.
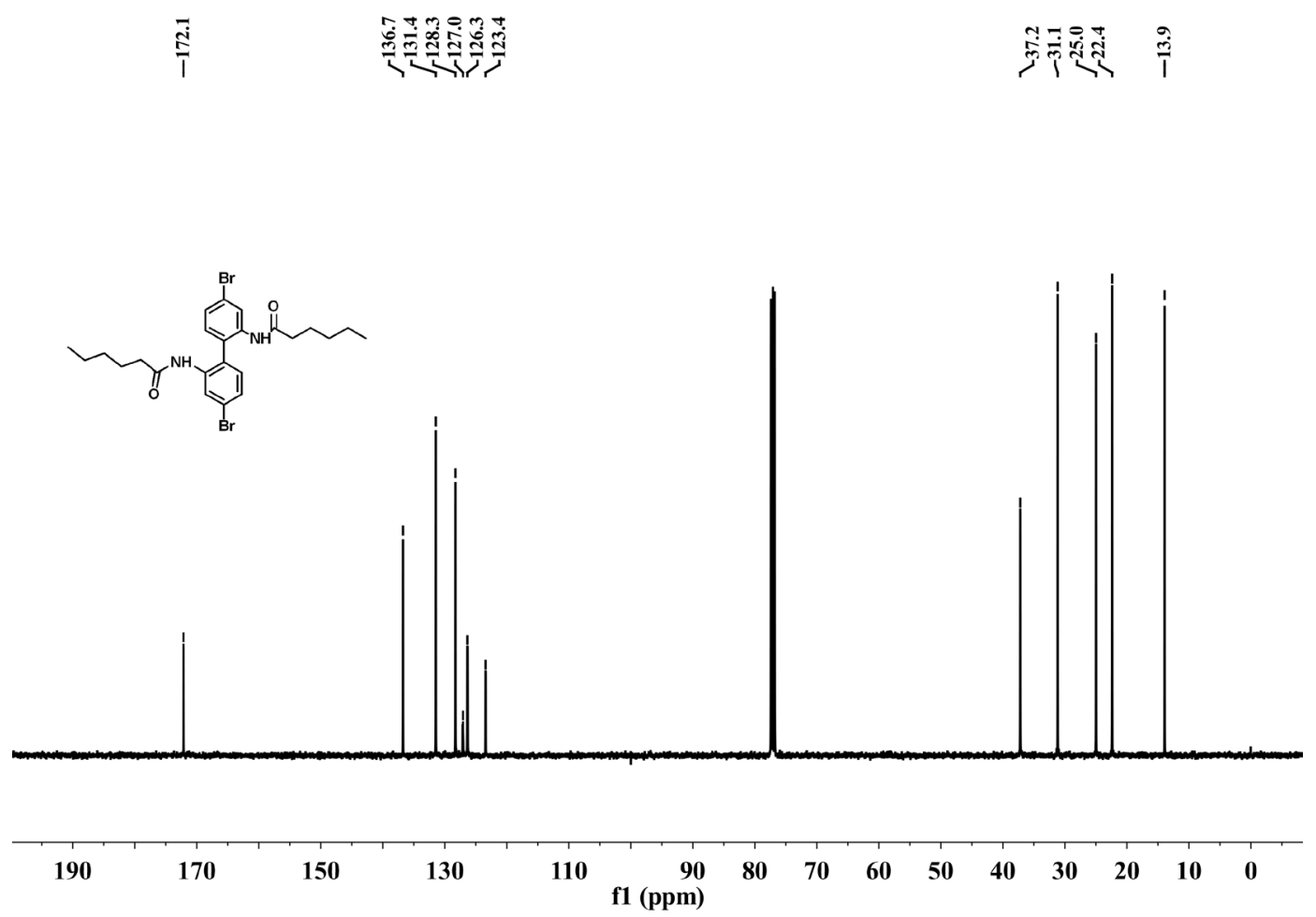

Figure S29. ${ }^{13} \mathrm{C}$ NMR spectrum of $\mathbf{A}_{\mathbf{3}} \mathbf{- 2}$ in $\mathrm{CDCl}_{3}$. 


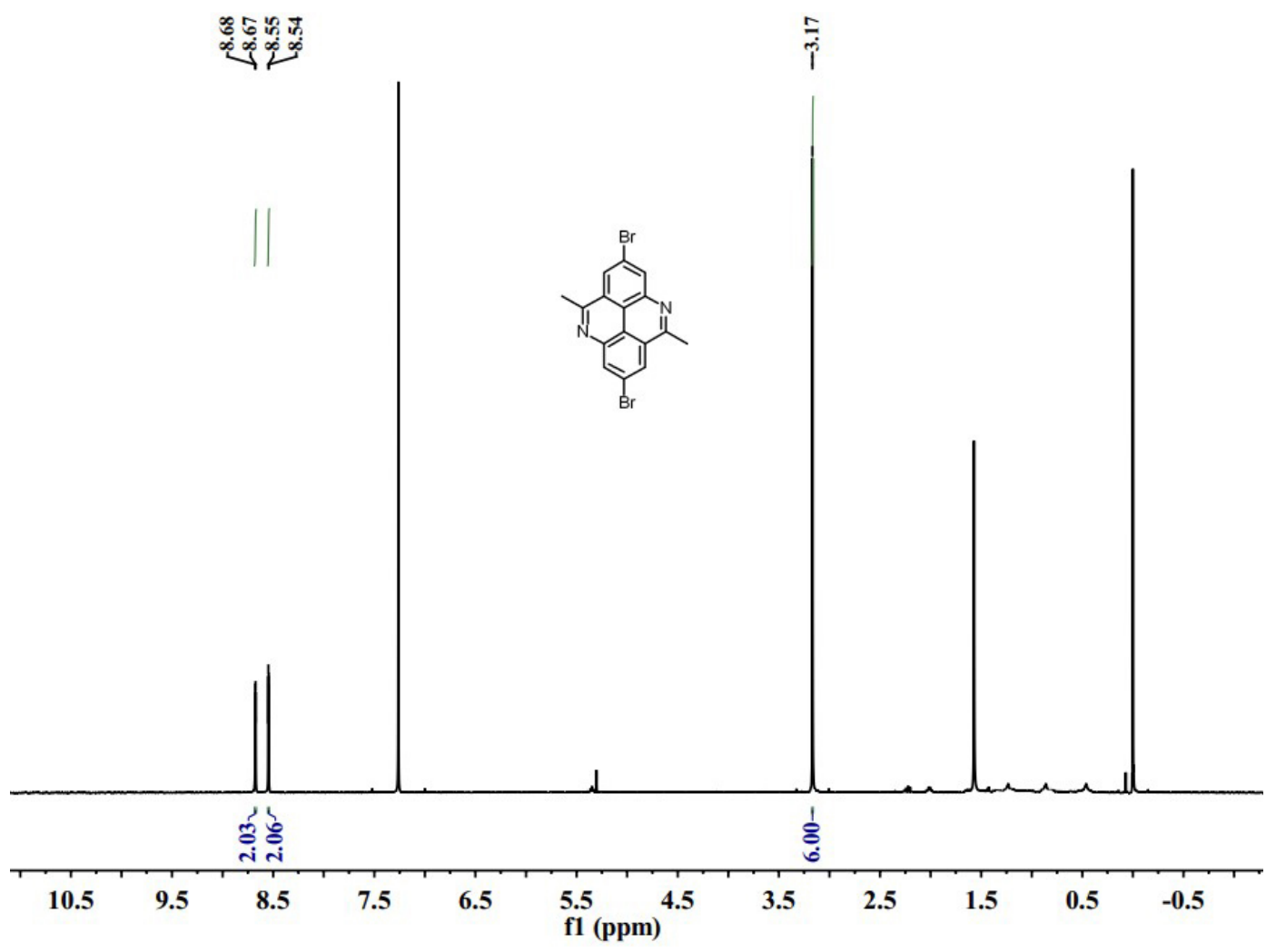

Figure S30. ${ }^{1} \mathrm{H}$ NMR spectrum of $\mathbf{A}_{\mathbf{4}} \mathbf{- 1}$ in $\mathrm{CDCl}_{3}$.

象家

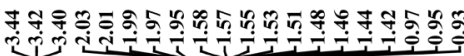

|
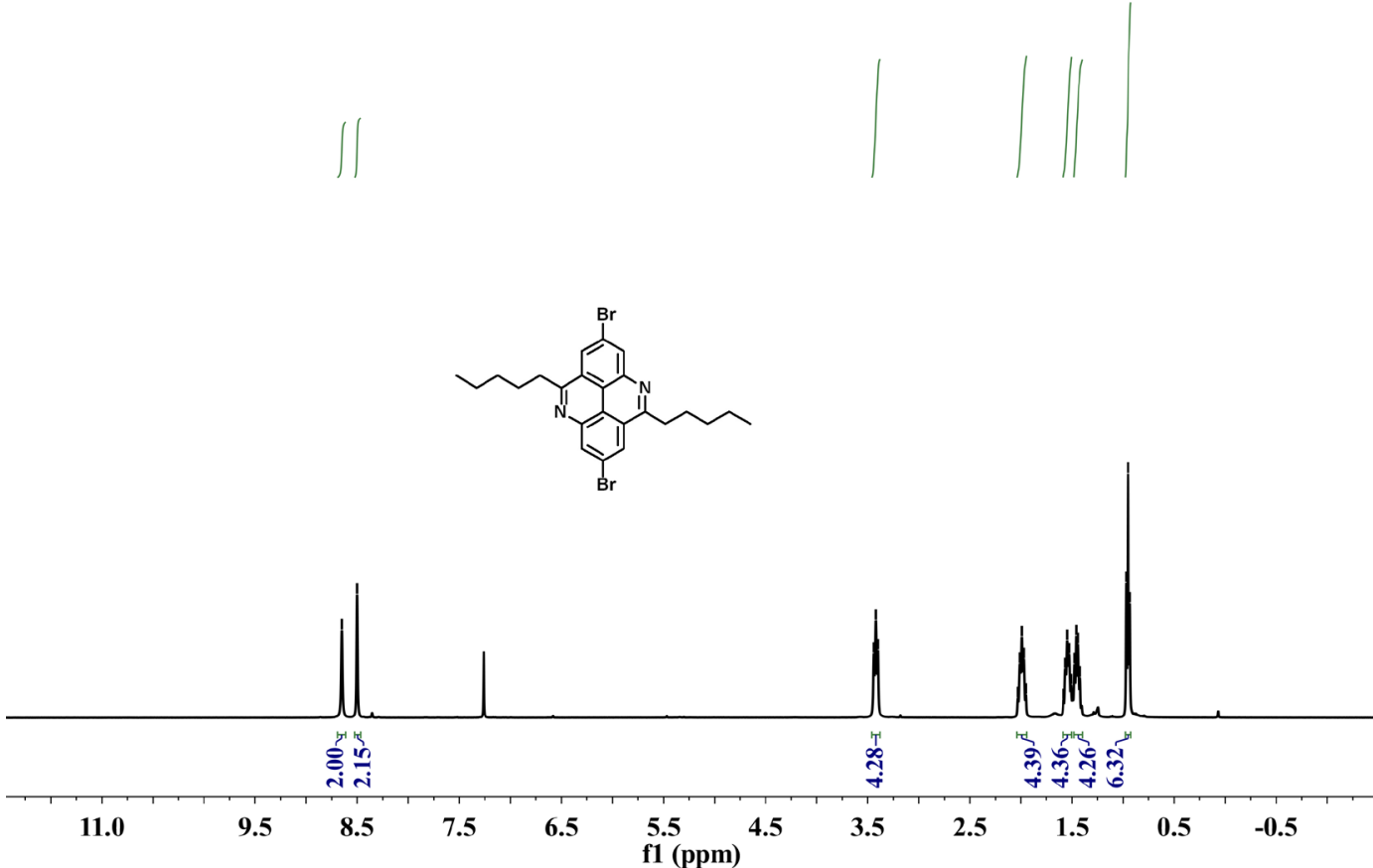

Figure S31. ${ }^{1} \mathrm{H}$ NMR spectrum of $\mathbf{A}_{\mathbf{4}} \mathbf{- 2}$ in $\mathrm{CDCl}_{3}$. 


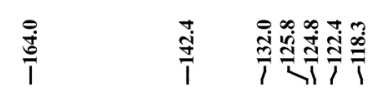

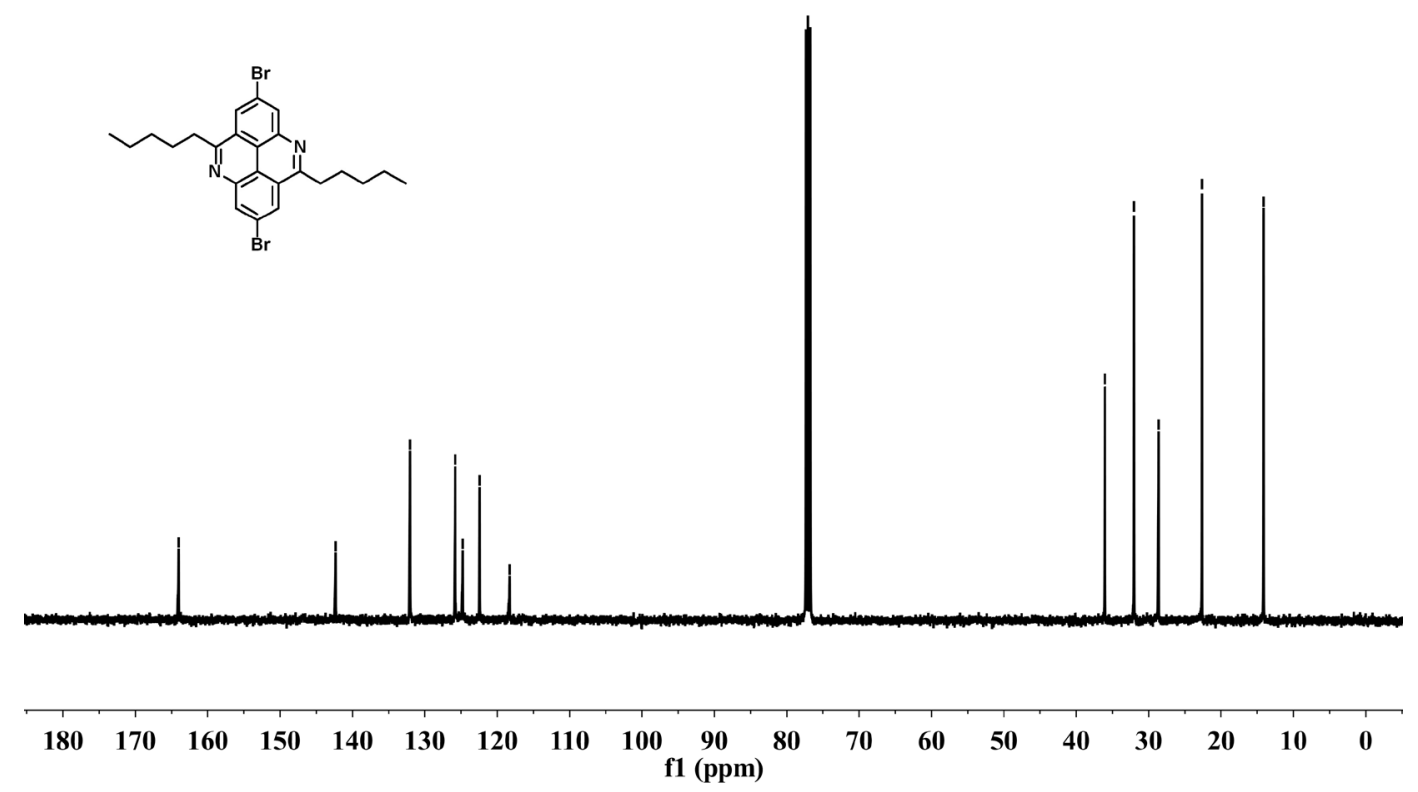

Figure S32. ${ }^{13} \mathrm{C}$ NMR spectrum of $\mathbf{A}_{\mathbf{4}} \mathbf{- 2}$ in $\mathrm{CDCl}_{3}$.
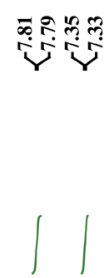

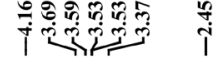
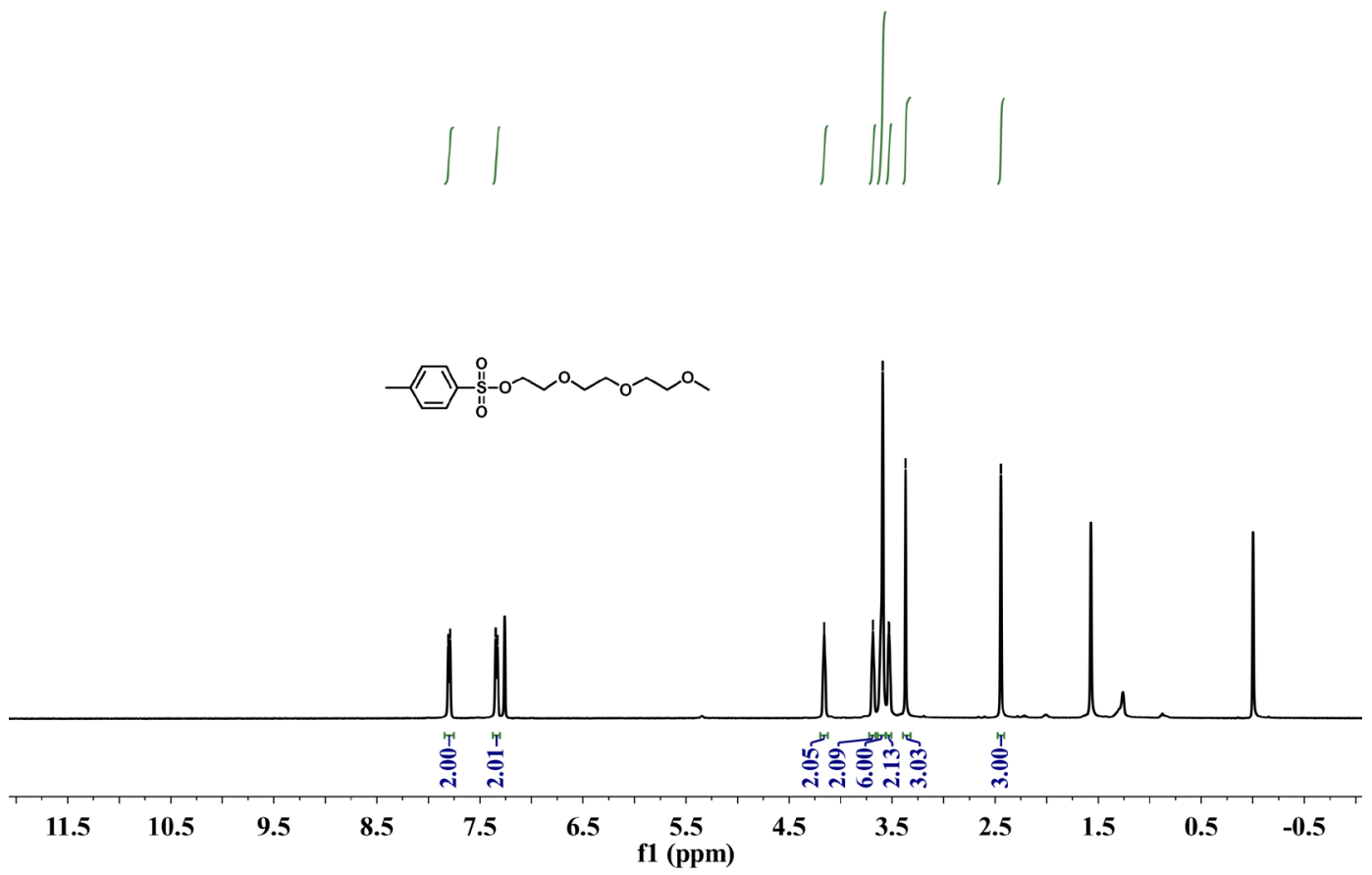

Figure S33. ${ }^{1} \mathrm{H}$ NMR spectrum of Ts-OTEG in $\mathrm{CDCl}_{3}$. 


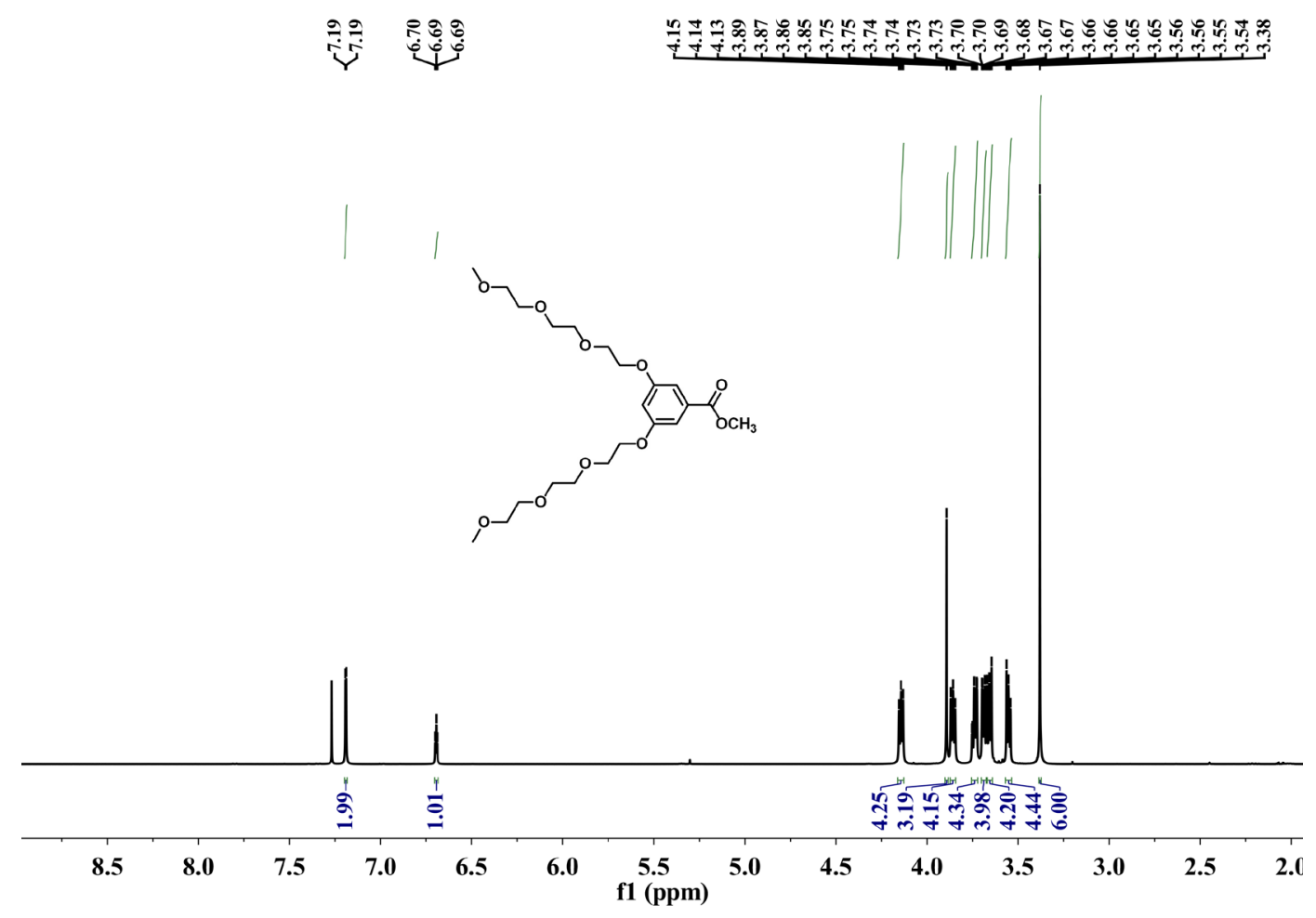

Figure S34. ${ }^{1} \mathrm{H}$ NMR spectrum of $\mathbf{B}_{1}$ in $\mathrm{CDCl}_{3}$.

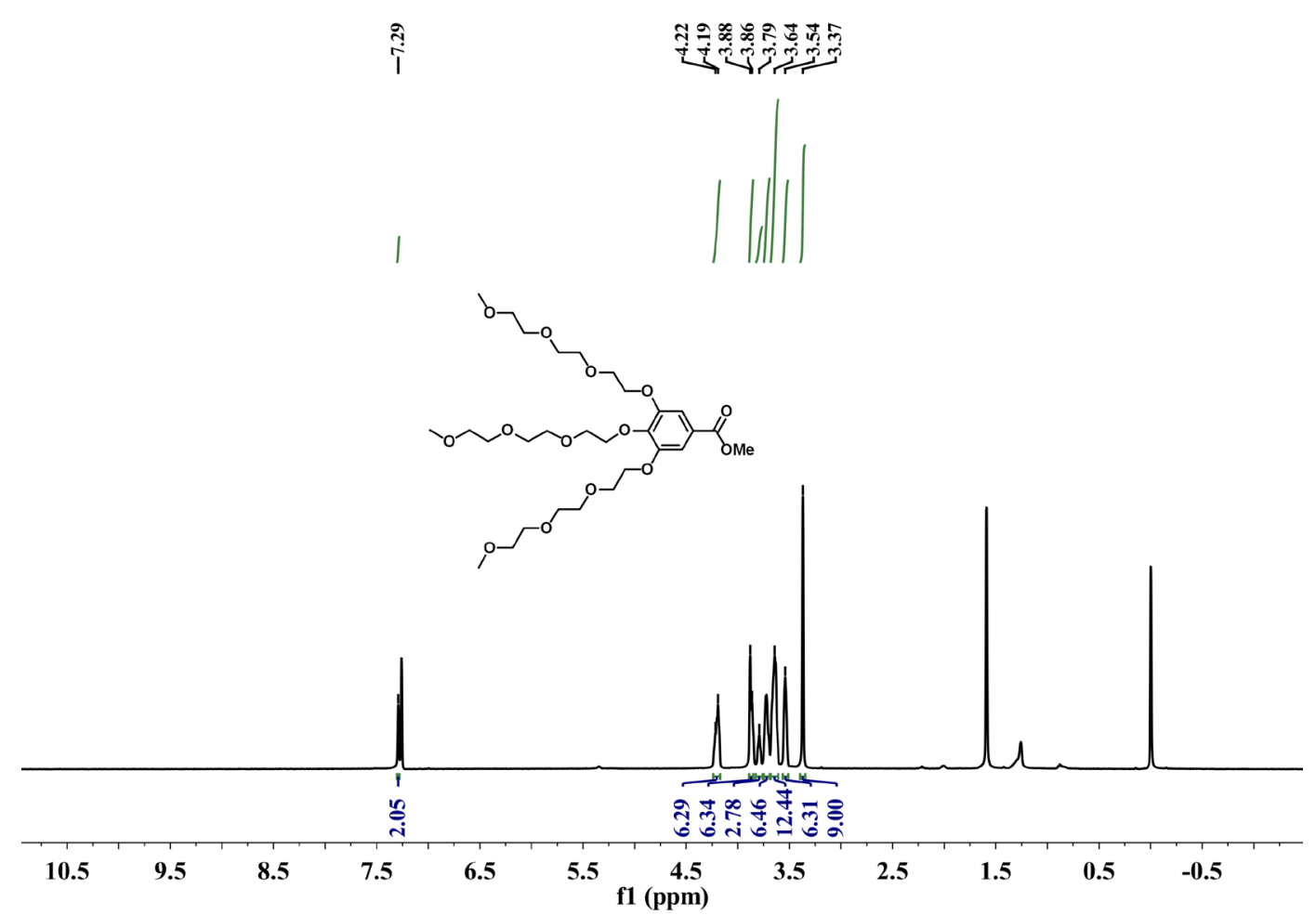

Figure S35. ${ }^{1} \mathrm{H}$ NMR spectrum of $\mathbf{C}_{\mathbf{1}}$ in $\mathrm{CDCl}_{3}$. 


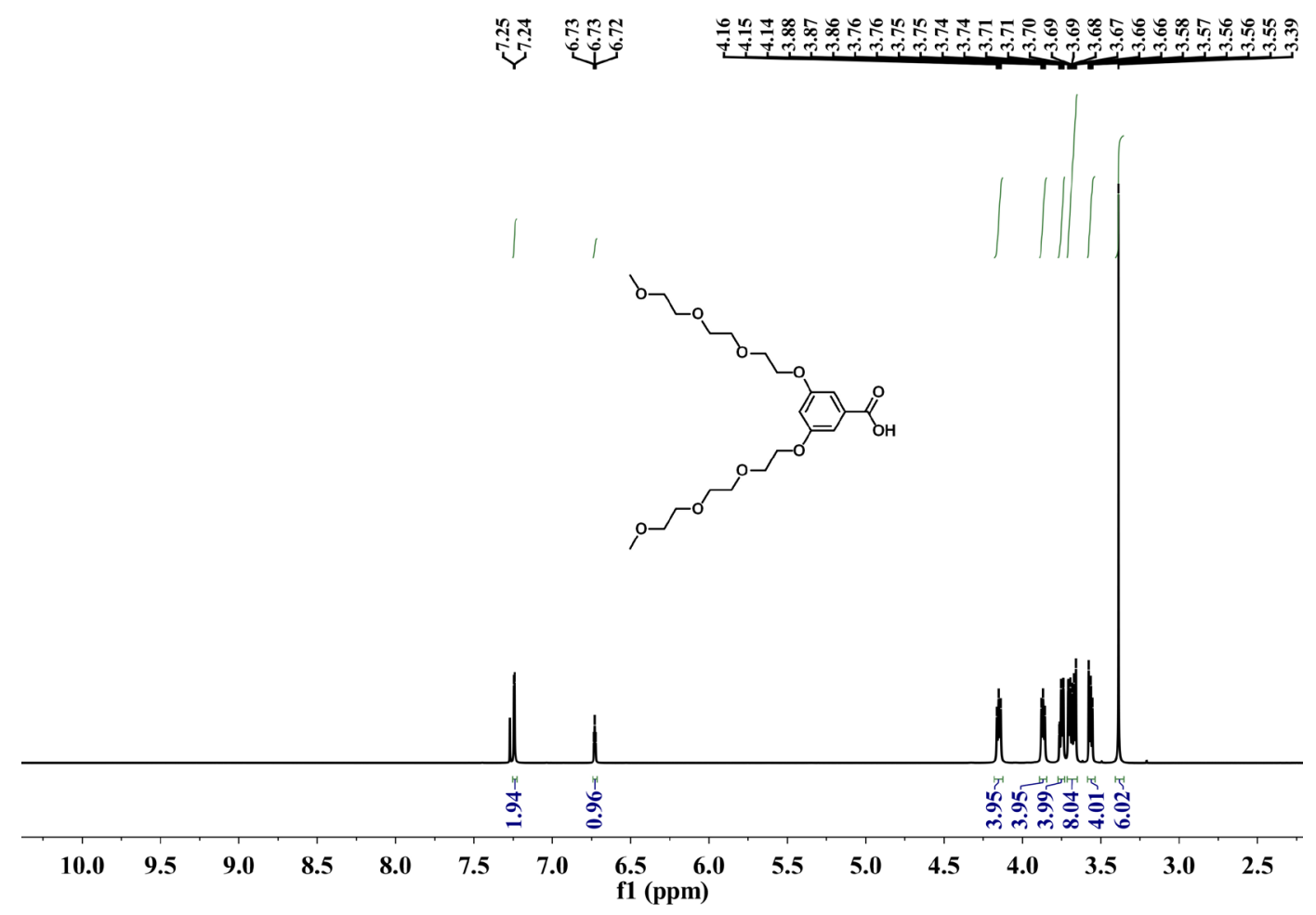

Figure S36. ${ }^{1} \mathrm{H}$ NMR spectrum of $\mathbf{B}_{2}$ in $\mathrm{CDCl}_{3}$.

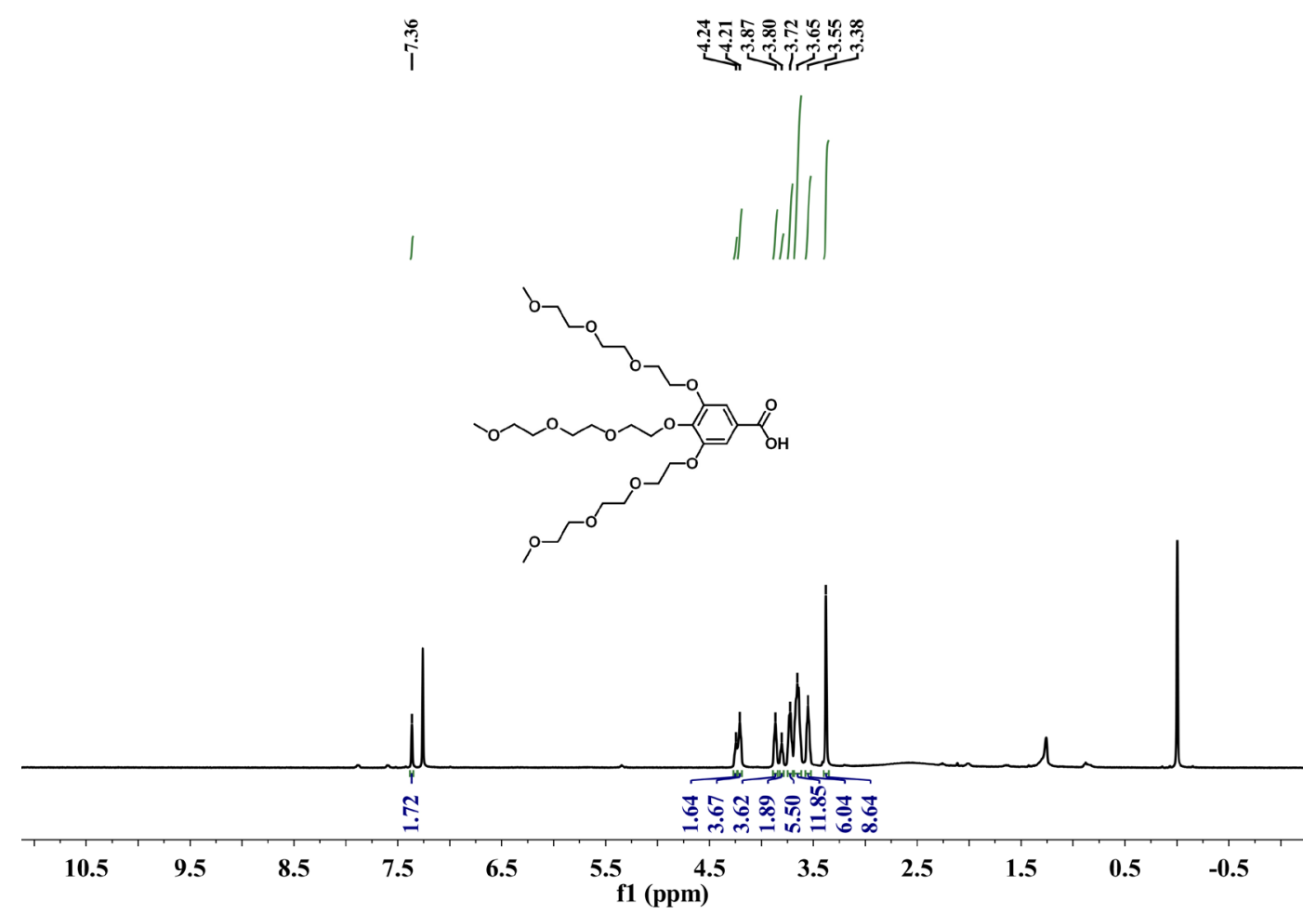

Figure S37. ${ }^{1} \mathrm{H}$ NMR spectrum of $\mathbf{C}_{2}$ in $\mathrm{CDCl}_{3}$. 


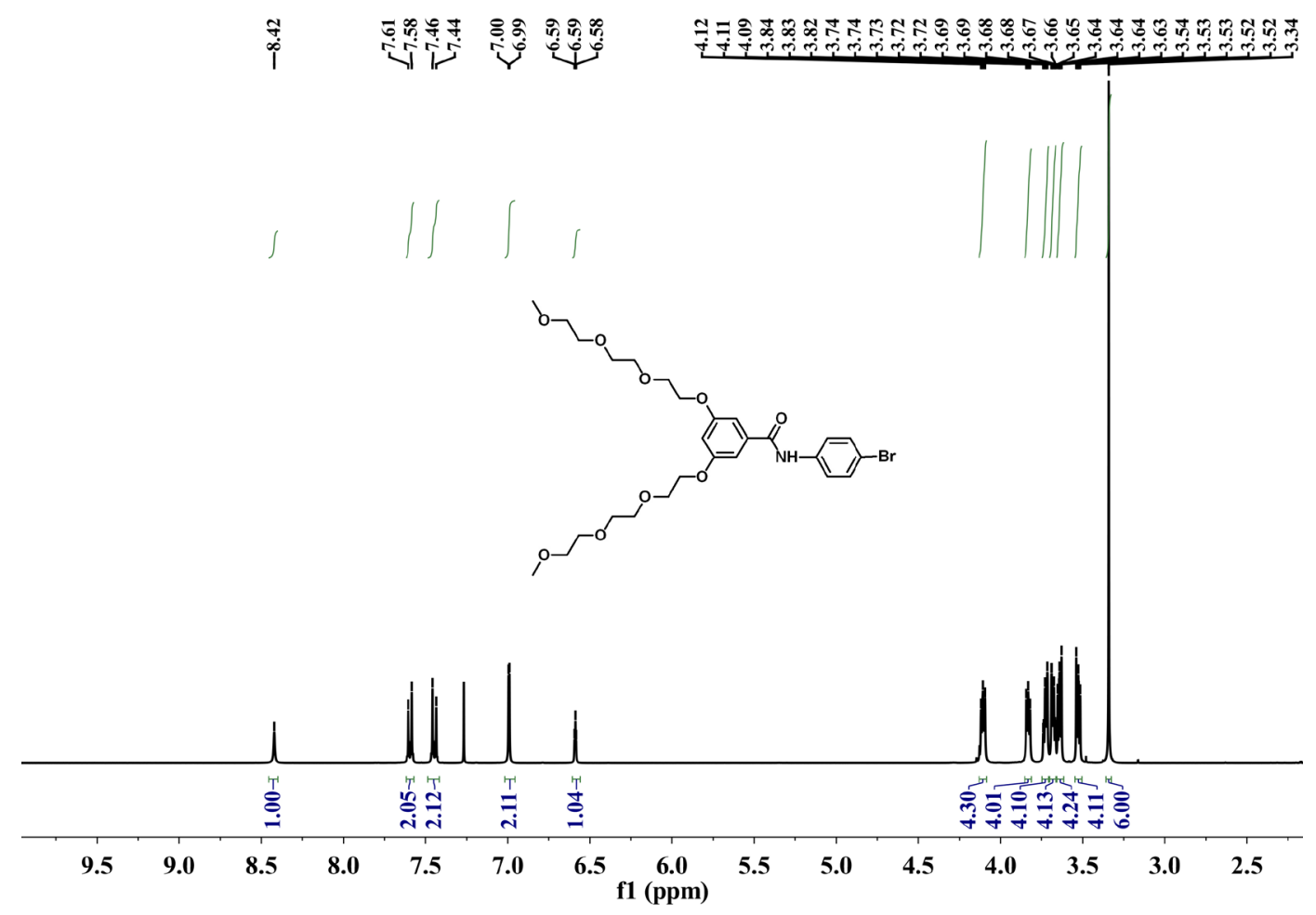

Figure S38. ${ }^{1} \mathrm{H}$ NMR spectrum of $\mathbf{B}_{3}$ in $\mathrm{CDCl}_{3}$.

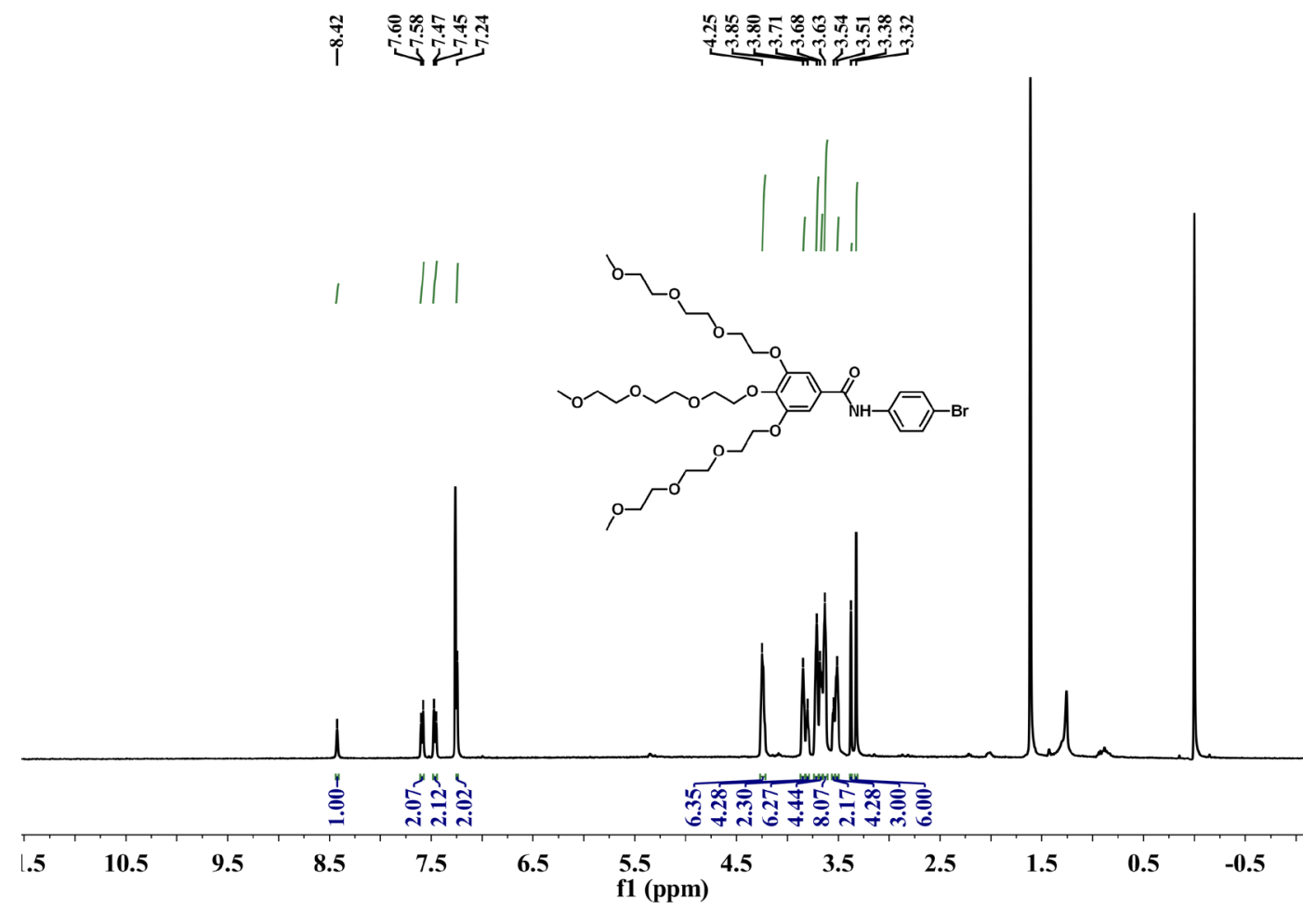

Figure S39. ${ }^{1} \mathrm{H}$ NMR spectrum of $\mathbf{C}_{3}$ in $\mathrm{CDCl}_{3}$. 


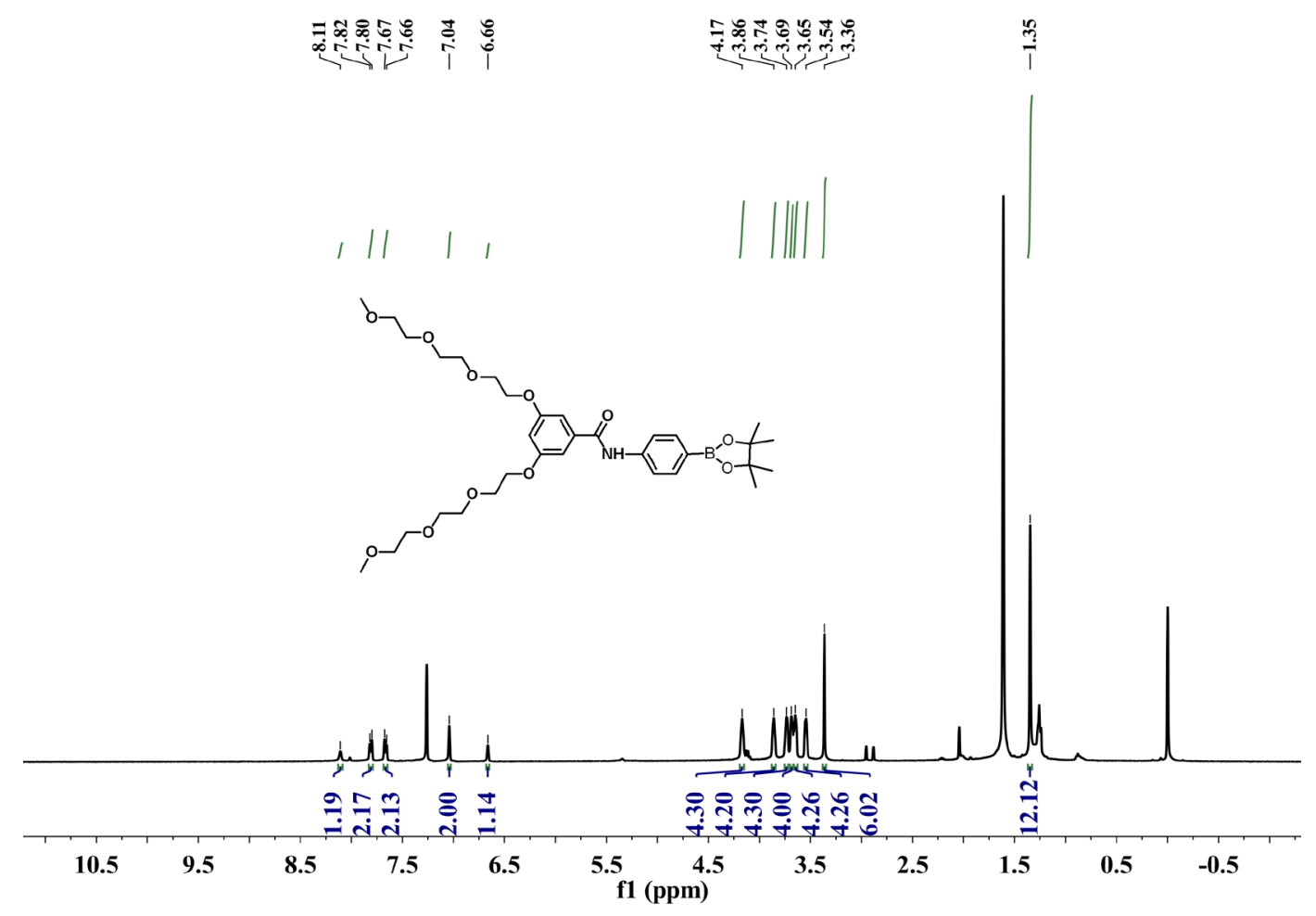

Figure S40. ${ }^{1} \mathrm{H}$ NMR spectrum of $\mathbf{B}_{4}$ in $\mathrm{CDCl}_{3}$.

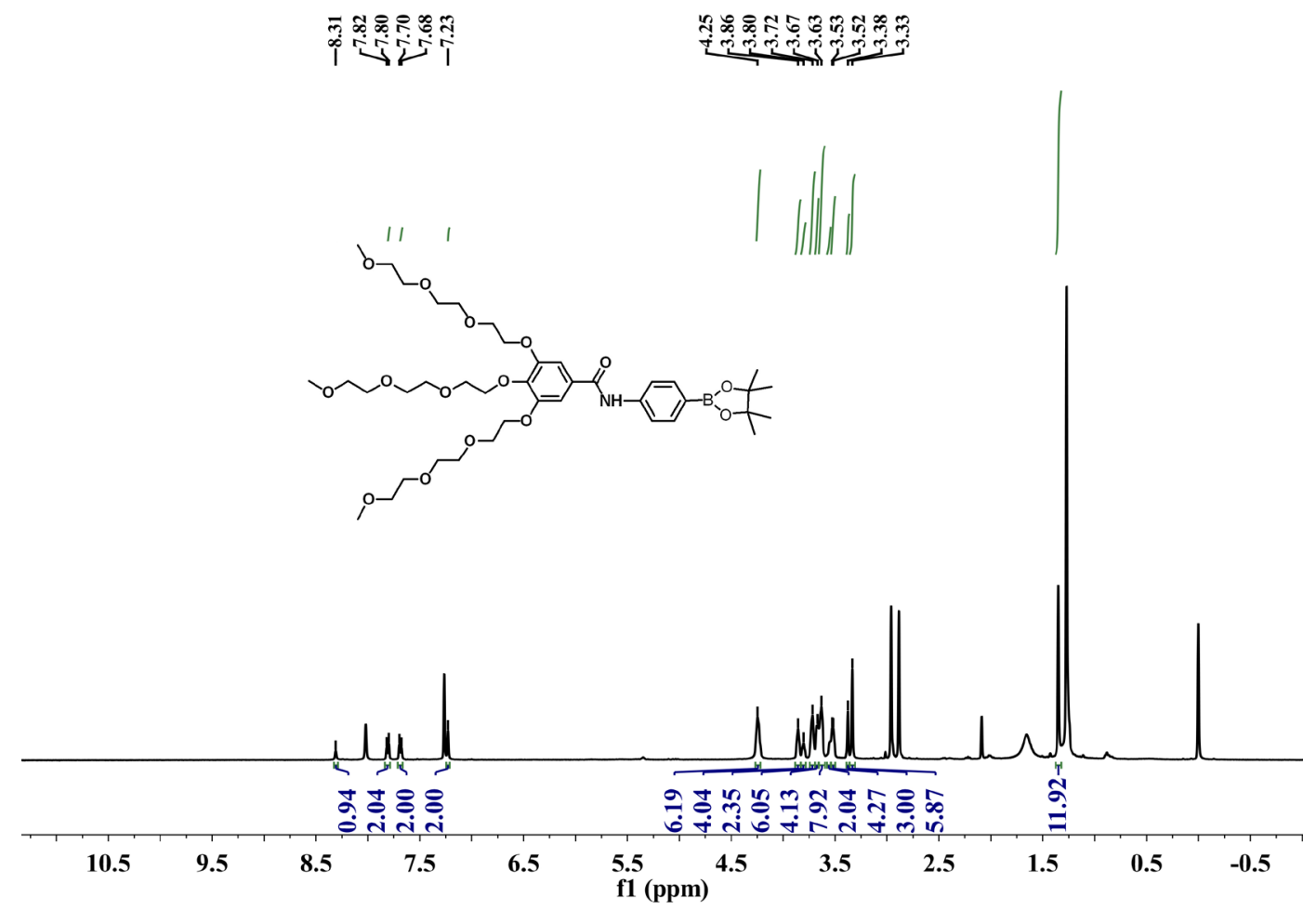

Figure S41. ${ }^{1} \mathrm{H}$ NMR spectrum of $\mathbf{C}_{4}$ in $\mathrm{CDCl}_{3}$. 


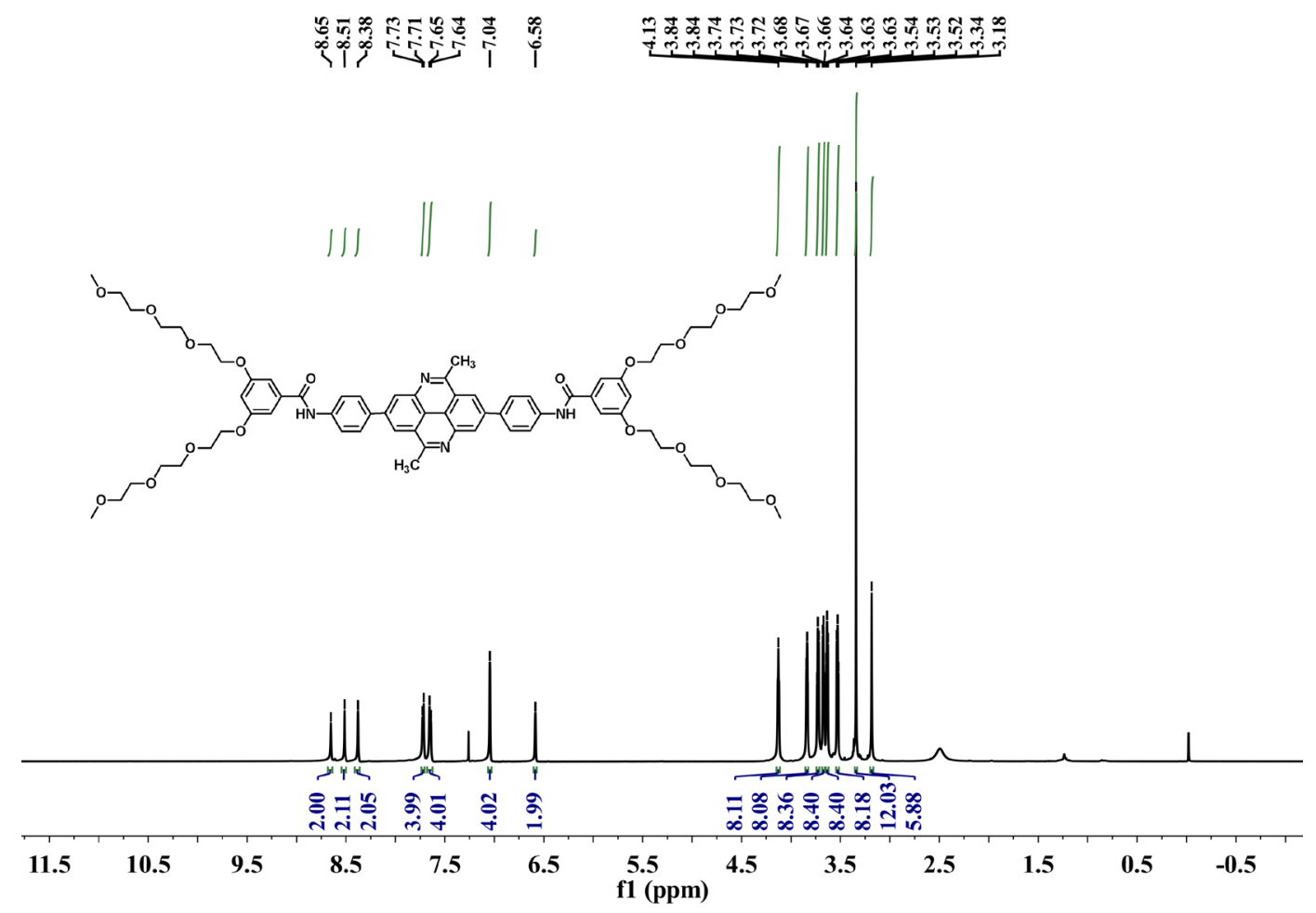

Figure S42. ${ }^{1} \mathrm{H}$ NMR spectrum of DPy-2-C1 in $\mathrm{CDCl}_{3}$.

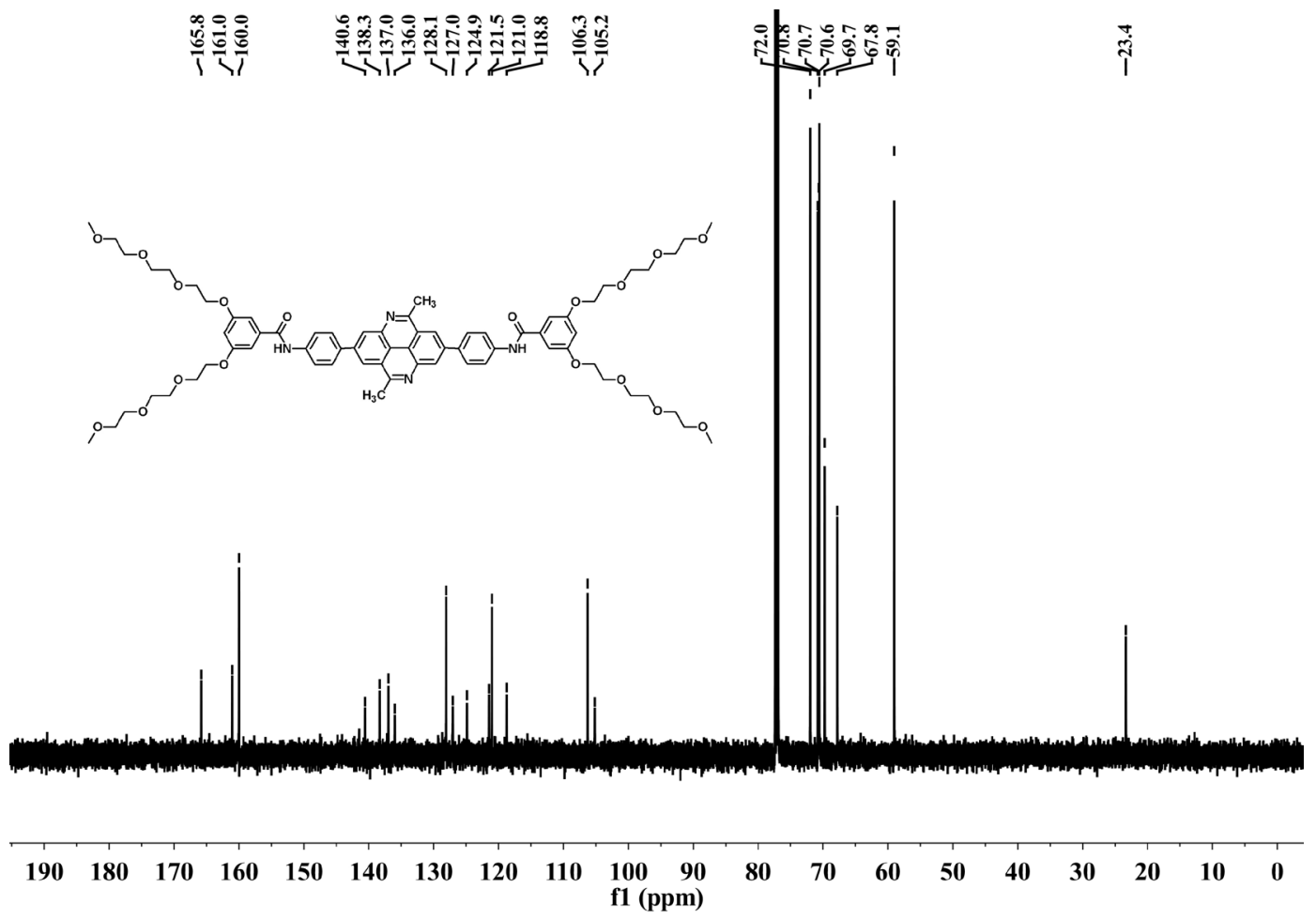

Figure S43. ${ }^{13} \mathrm{C}$ NMR spectrum of DPy-2-C1 in $\mathrm{CDCl}_{3}$. 


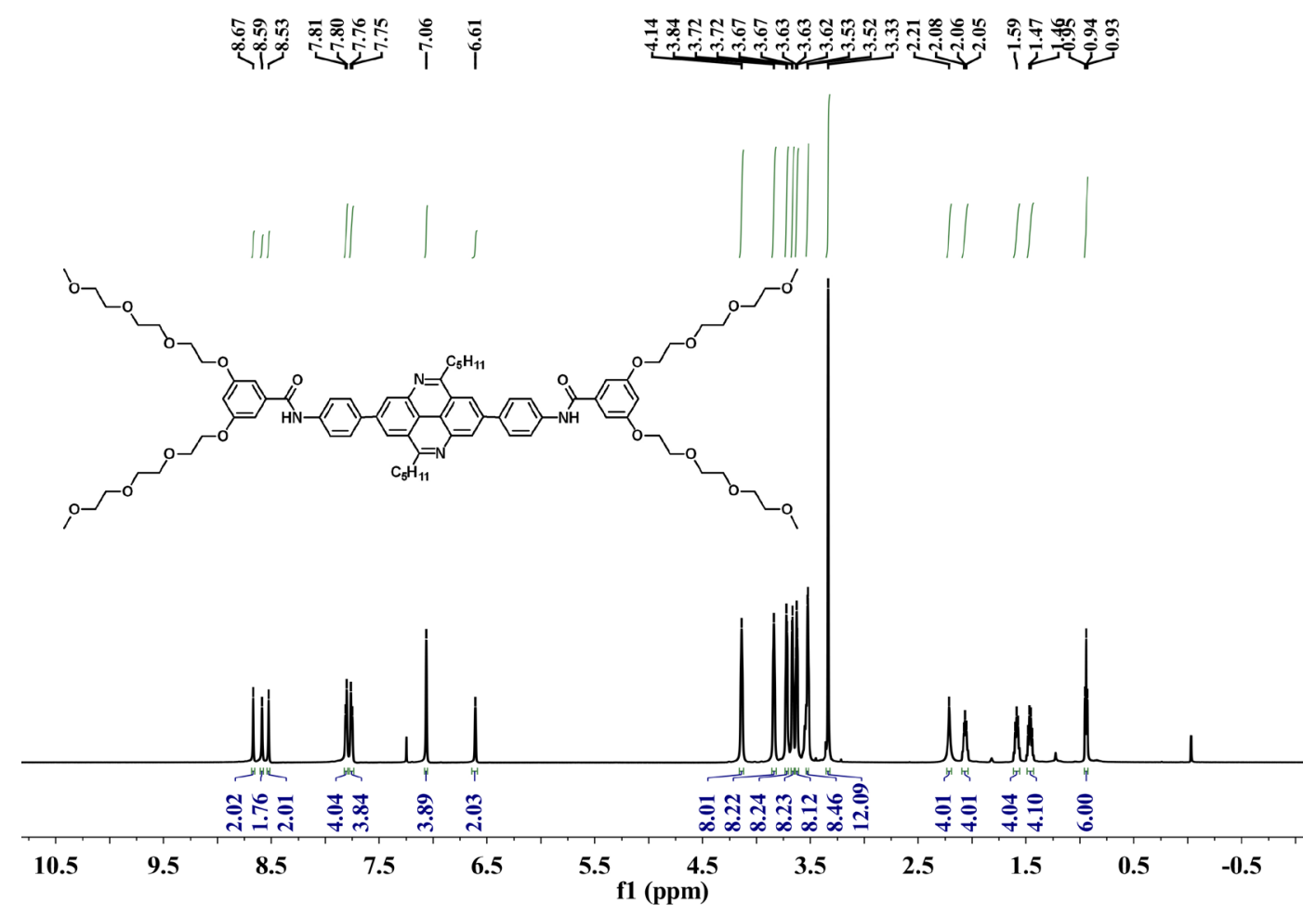

Figure S44. ${ }^{1} \mathrm{H}$ NMR spectrum of DPy-2-C5 in $\mathrm{CDCl}_{3}$.

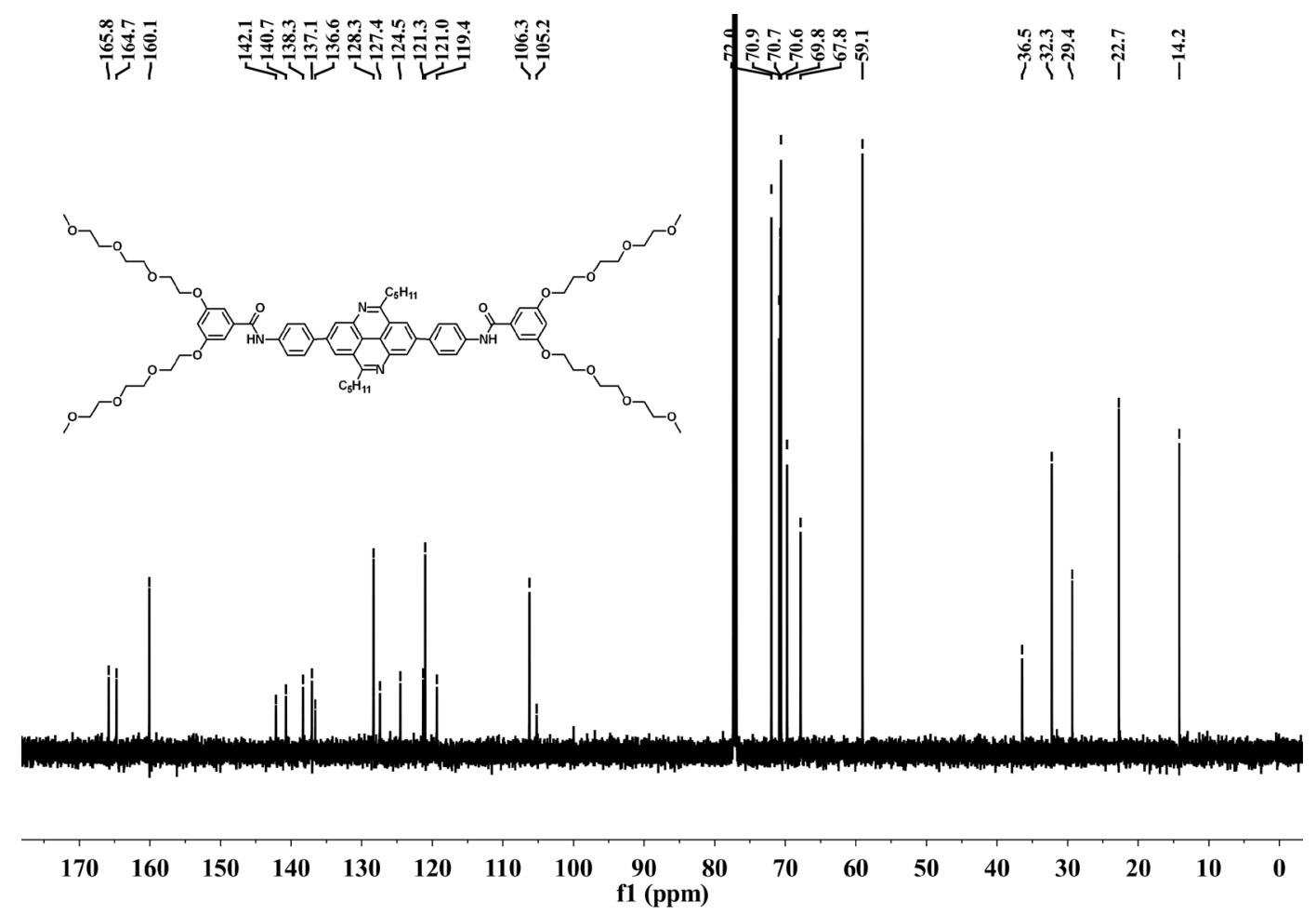

Figure S45. ${ }^{13} \mathrm{C}$ NMR spectrum of DPy-2-C5 in $\mathrm{CDCl}_{3}$. 


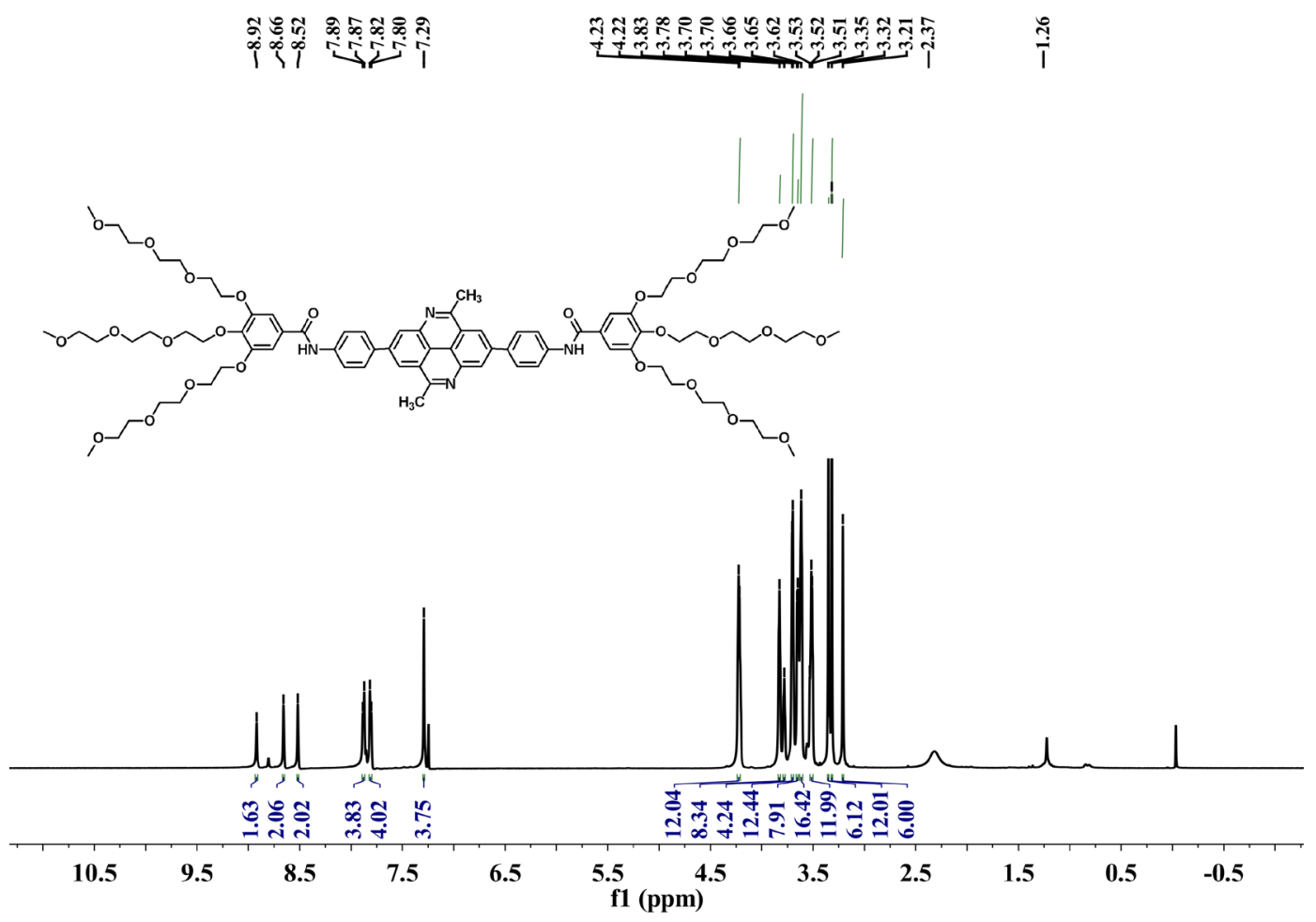

Figure S46. ${ }^{1} \mathrm{H}$ NMR spectrum of DPy-3-C1 in $\mathrm{CDCl}_{3}$.

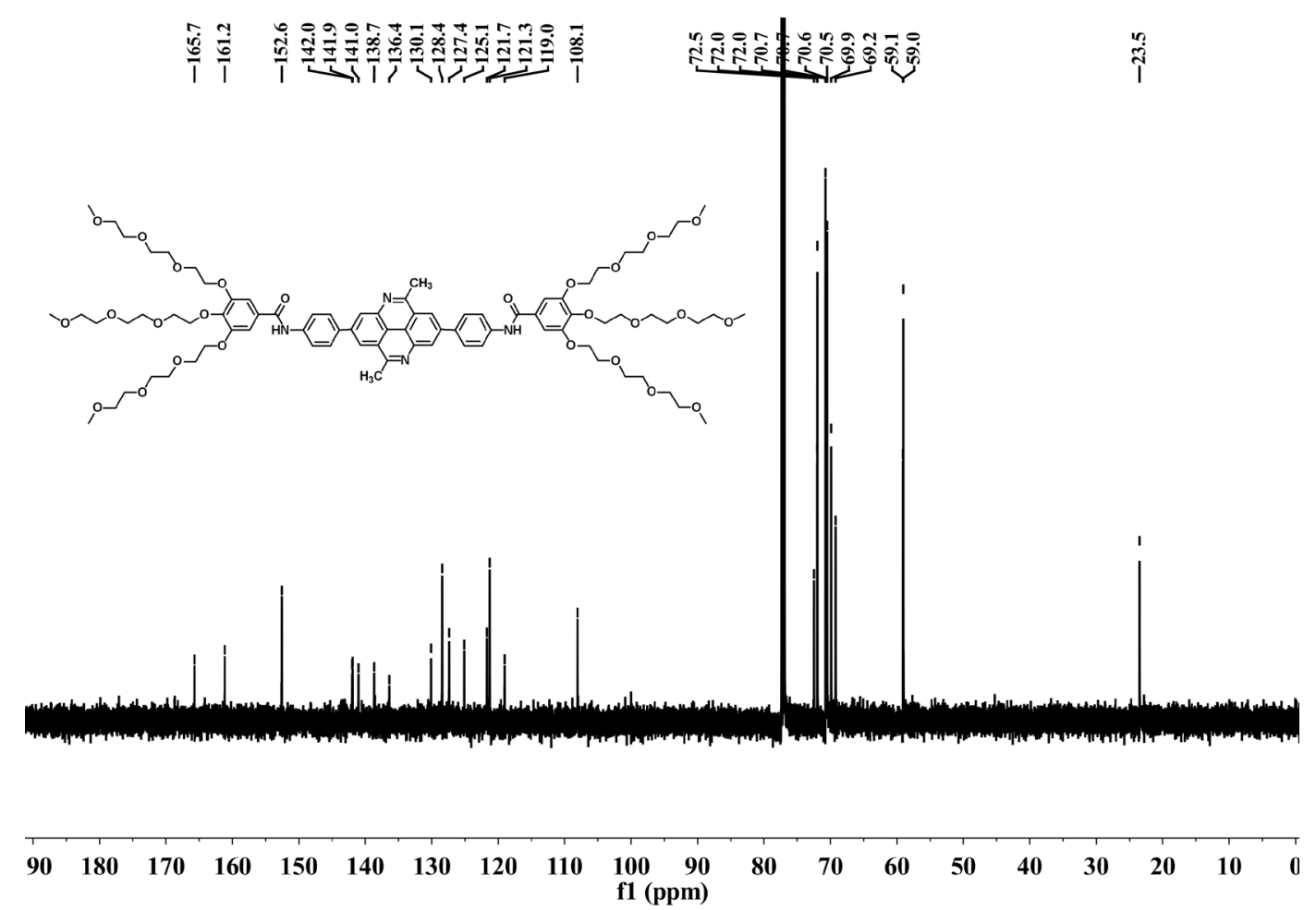

Figure S47. ${ }^{13} \mathrm{C}$ NMR spectrum of DPy-3-C1 in $\mathrm{CDCl}_{3}$. 


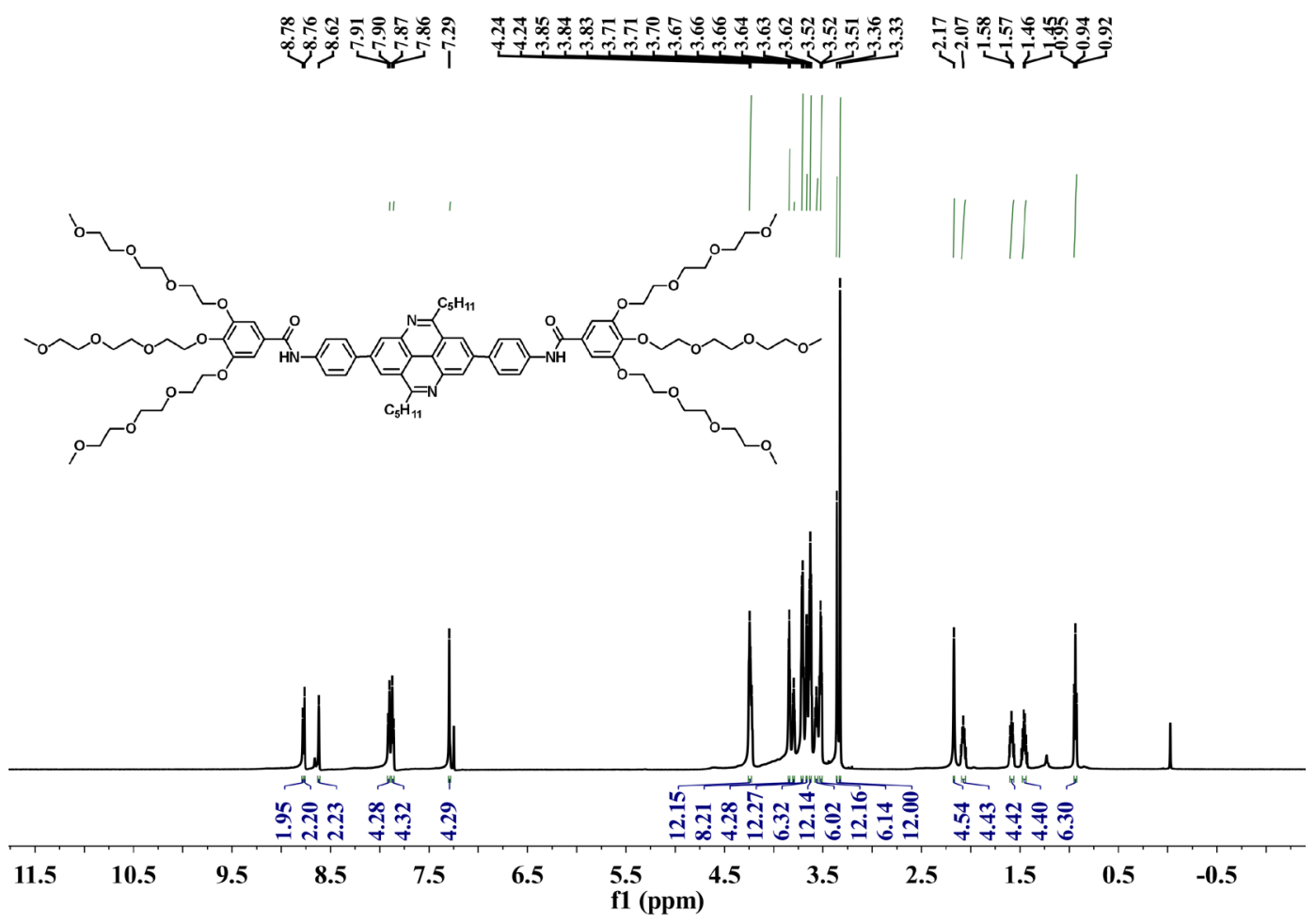

Figure S48. ${ }^{1} \mathrm{H}$ NMR spectrum of DPy-3-C5 in $\mathrm{CDCl}_{3}$.

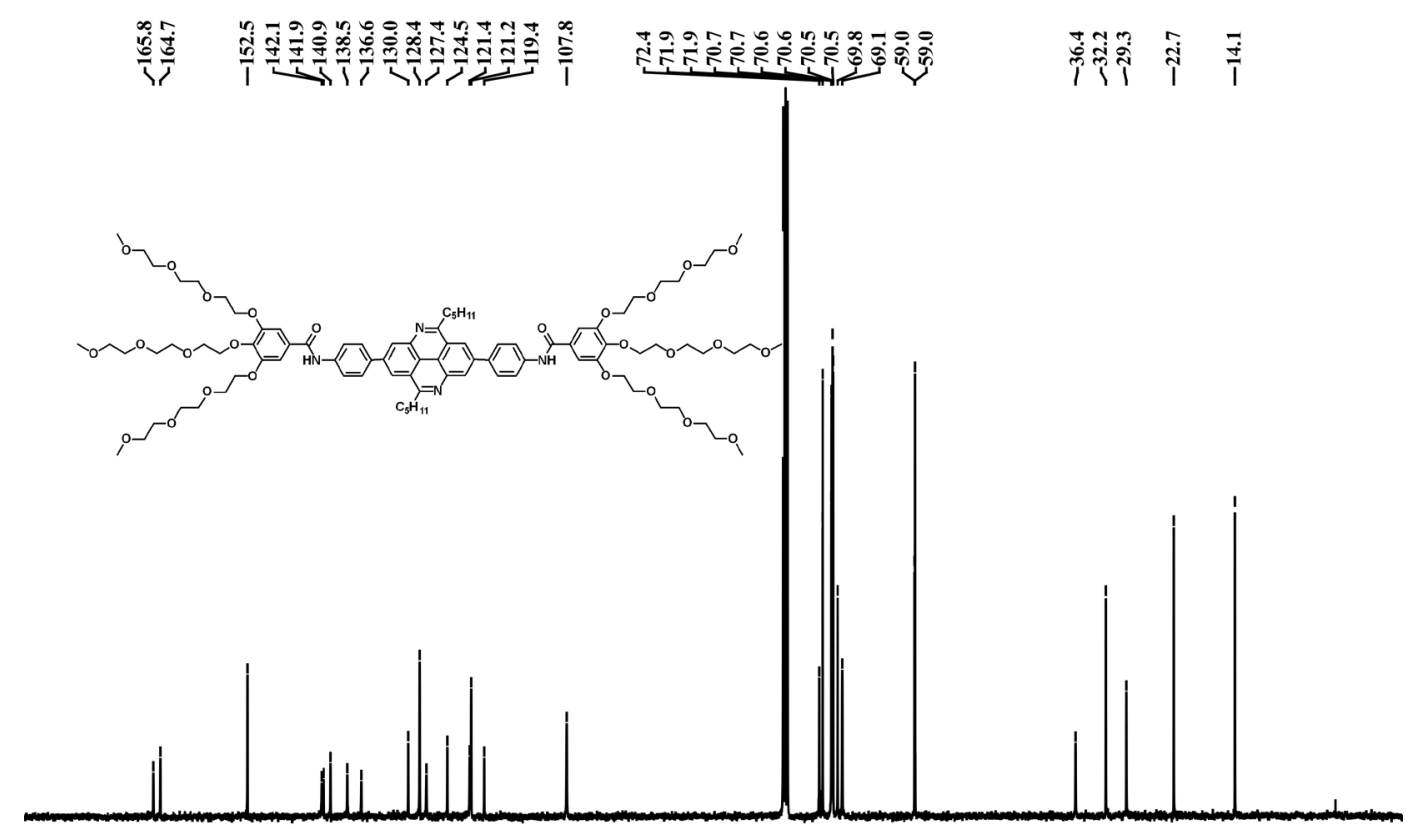

$\begin{array}{lllllllllllllllllllll}180 & 170 & 160 & 150 & 140 & 130 & 120 & 110 & 100 & \underset{f 1}{90} & 80 & 70 & 60 & 50 & 40 & 30 & 20 & 10 & 0 & \end{array}$

Figure S49. ${ }^{13} \mathrm{C}$ NMR spectrum of DPy-3-C5 in $\mathrm{CDCl}_{3}$. 


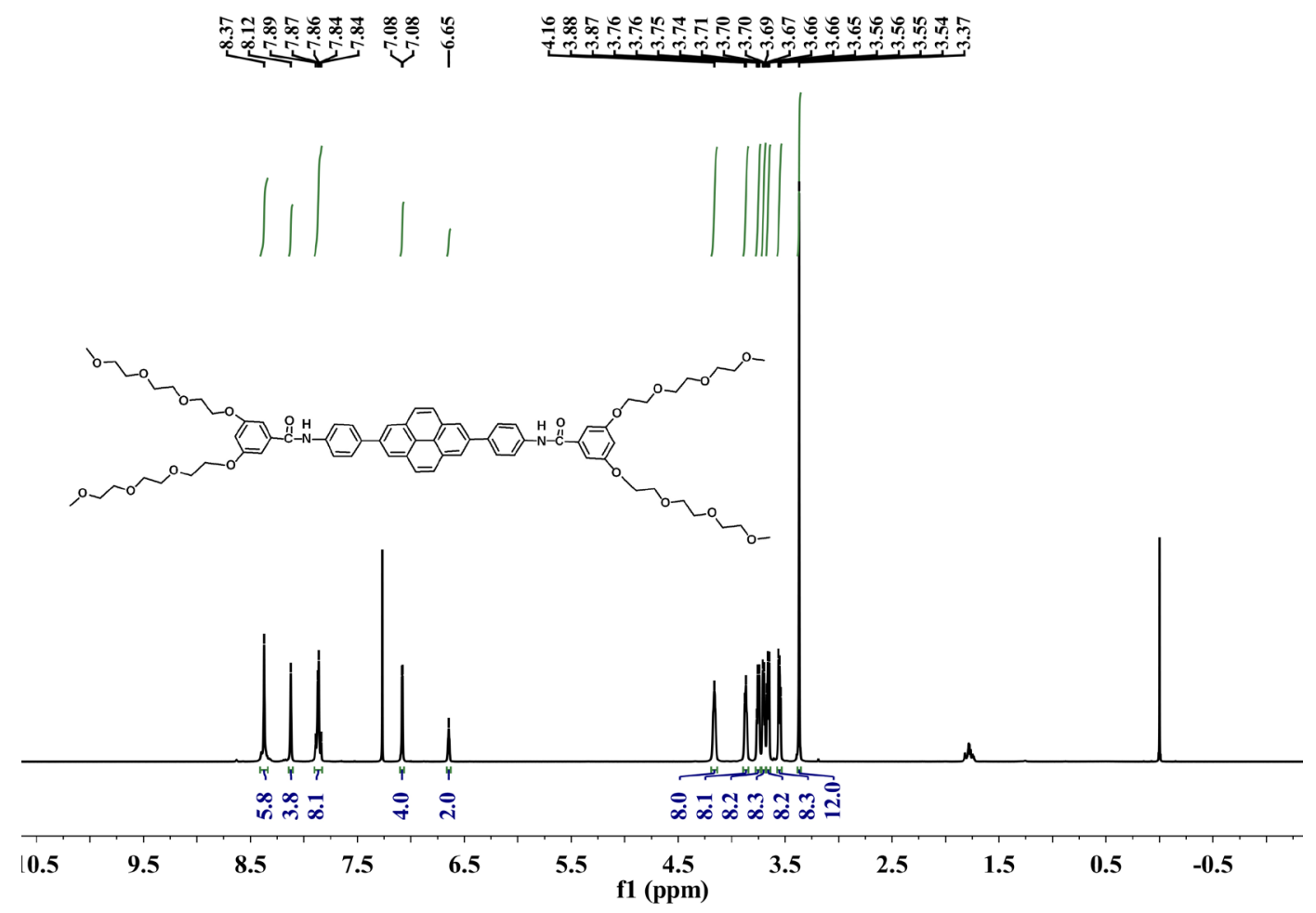

Figure S50. ${ }^{1} \mathrm{H}$ NMR spectrum of $\mathbf{P y - 2}$ in $\mathrm{CDCl}_{3}$.

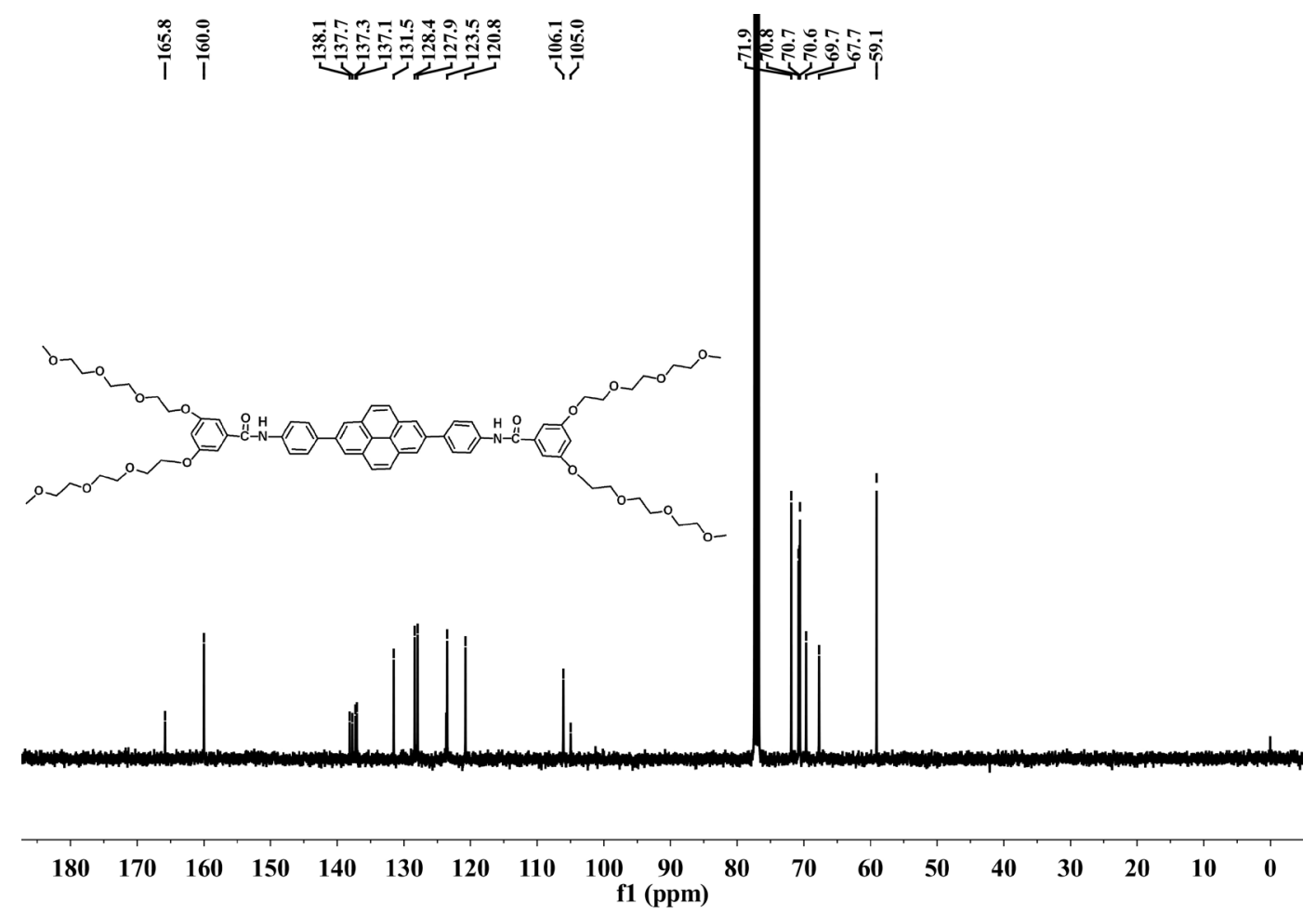

Figure S51. ${ }^{13} \mathrm{C}$ NMR spectrum of $\mathbf{P y}-\mathbf{2}$ in $\mathrm{CDCl}_{3}$.

\section{References}

(1) Tolman, C. A.; Seidel, W. C.; Gerlach, D. H. Triarylphosphine and ethylene complexes of zerovalent nickel, palladium, and platinum. J. Am. Chem. Soc. 1972, 94, 2669-2676. 
(2) Crawford, A. G.; Liu, Z.; Mkhalid, I. A. I.; Thibault, M. H.; Schwarz, N.; Alcaraz, G.; Steffen, A.; Collings, J. C.; Batsanov, A. S.; Howard, J. A. K.; Marder, T. B. Synthesis of 2 - and 2,7 Functionalized Pyrene Derivatives: An Application of Selective C-H Borylation. Chem.- Eur. J. 2012, $18,5022-5035$. 